\title{
CATÁLOGO DE LOS MEGACHILIDAE DEL MEDITERRÁNEO OCCIDENTAL (HYMENOPTERA, APOIDEA). I. OSMIINI ${ }^{1}$
}

\author{
C. Ornosa*, F. Torres** \& F. J. Ortiz-Sánchez***
}

\begin{abstract}
RESUMEN
El catálogo objeto de este trabajo es una primera entrega de una serie de tres que los autores han realizado sobre la familia Megachilidae en el área mediterránea occidental, como base de la revisión que se está llevando a cabo sobre los megaquílidos ibéricos. En esta ocasión, se trata de los componentes de la tribu Osmiini, formada por 10 géneros, 33 subgéneros y 243 especies, muchas de ellas diferenciadas en varias poblaciones subespecíficas, que hacen un total de 278 y asimismo se incluyen. De todos los taxones, además de la correspondiente discusión, si procede, se incluye su lista sinonímica y la distribución geográfica.
\end{abstract}

Palabras clave: Hymenoptera, Apoidea, Megachilidae, Osmiini, catálogo, Mediterráneo occidental.

\section{ABSTRACT \\ A catalogue of the western Mediterranean Megachilidae (Hymenoptera, Apoidea). I. Osmiini}

The present work is the first of three by the authors that make up a catalogue of the family Megachilidae in the western Mediterranean region, based on the revision currently undertaken on Iberian Megachilidae. It includes taxa of the tribe Osmiini, their synonymies, discussion, when necessary, as well as their geographic distribution. The results of our study indicate that the fauna of this tribe in the western Mediterranean is composed of 10 genera, 33 subgenera, 243 species and 278 subspecies, all of which are included.

Key words: Hymenoptera, Apoidea, Megachilidae, Osmiini, catalogue, western Mediterranean.

* Departamento de Zoología y Antropología Física. Facultad de Biología. Universidad Complutense. c/ José Antonio Nováis, 2. E-28040 Madrid, España. E-mail: paddy@bio.ucm.es

** Departamento de Biología Animal, Ecología, Parasitología y Edafología. Universidad de Salamanca. Campus Miguel de Unamuno s/n. E-37071 Salamanca, España. E-mail: torres@usal.es

*** Grupo de Investigación "Transferencia de I+D en el Área de Recursos Naturales". Universidad de Almería. E-04120 La Cañada de San Urbano (Almería), España. E-mail: fjortiz@ual.es

1 Subvencionado por el Proyecto CGL2004-04680-C10-05. 


\section{Introducción}

El catálogo objeto de este trabajo forma parte de una serie de tres sobre la familia Megachilidae en el área mediterránea occidental, que se ha realizado como base para la revisión que paralelamente, dentro del Proyecto Fauna Ibérica, se está llevando a cabo sobre los megaquílidos ibéricos. En esta ocasión, se abordan los componentes de la tribu Osmiini.

Los megaquílidos presentan una distribución prácticamente mundial en algunos de sus géneros que abarca los reinos Holártico, Australiano y Neotropical, en las regiones biogeográficas Neártica, Paleártica, Etiópica, Oriental, Australiana y Neozelandesa, desde zonas subárticas a desiertos y áreas tropicales (Michener, 2000).

Al igual que sucede con el resto de la fauna de esta familia de apoideos, el conocimiento que se tenía hasta ahora sobre los Osmiini del territorio considerado está basado en una información que, si bien es abundante, adolece de estar dispersa y fragmentada y contar con escasos trabajos de conjunto, con excepción de alguno aislado (Stanek, 1964). Existen, no obstante, obras, incluso catálogos de otros territorios (Griswold \& Parker, 1987; van der Zanden, 1988a, 1988b; Comba \& Comba, 1991, 2001; Erlandsson, 1991; Rasmont, et al., 1995; Schwarz et al. 1996; Banaszak \& Romasenko, 2001; Quaranta et al., 2004, etc.), pero, en general, cubren parcialmente el área considerada o no descienden a niveles taxonómicos inferiores. Además, como es habitual en este grupo de insectos, están sujetas a opiniones contrapuestas y diversas concepciones.

El objetivo fundamental de este estudio es realizar el catálogo de los Osmiini del área mediterránea occidental, clarificar cuáles son los componentes de la tribu, realizar su lista sinonímica y establecer la distribución geográfica, hasta nivel subespecífico. Dos estudios complementarios de éste, que en plazo breve publicarán los mismos autores, corresponden a los catálogos de las tribus Lithurgini y Megachilini, por un lado, y Anthidiini y Dioxyini, por otro.

\section{Material y métodos}

El ámbito corológico del área mediterránea occidental se escogió como un territorio más amplio que comprendiera a todas las posibles especies ibéricas y sus distintos orígenes, por un lado, y por su importancia biogeográfica dentro de la región paleártica, por otro. El catálogo, por lo tanto, comprende especies del norte de África, sin incluir las de localidades más meridionales, netamente desérticas, de Argelia y Marruecos (aunque ante la duda sobre su dispersión se ha preferido incluirlas), y las que se extienden en Europa, desde la Península Ibérica y Baleares, hasta Grecia por el este, cuando forman parte de otras distribuciones más occidentales; no se han incluido aquéllas que desde el Mediterráneo oriental llegan hasta el entorno balcánico o las que constituyen fauna exclusiva de Grecia, la antigua Yugoslavia, de Italia o de Túnez.

Desde el punto de vista sistemático, se sigue en general a Michener (2000) para géneros y subgéneros y, por proximidad geográfica, también a Pagliano (1994), Rasmont et al. (1995), Schwarz et al. (1996) y Ebmer (2001, 2003), pero incluyendo posibles matices o variaciones de los diferentes autores, que se añaden o señalan, si procede. Éste ha sido el caso seguido en la adopción de ciertos subgéneros, por ejemplo, o en la consideración de las subespecies. Se ha prestado especial atención, además, a las citas y publicaciones del norte de África, normalmente menos contempladas en estudios paleárticos, sobre todo cuando se trata de publicaciones antiguas (Lucas, 1849; Dufour, 1853; Dours, 1873; Pérez, 1890, 1895; Vachal, 1891, 1910; Buysson, 1899; Ferton, 1890; Alfken, 1914; Morice, 1916; Dusmet, 1920; Friese, 1898, 1899a, 1899b, 1899c, 1921; Saunders, 1908; Schulthess, 1924; Benoist, 1927, 1928b, 1931a, 1931b, 1934a, 1934b, 1943, 1950, 1969; Nadig, 1933; Berland, 1943; Tkalcu, 1975b; Warncke, 1991b; van der Zanden, 1992a, 1992b, por ejemplo).

Por otro lado, como en el catálogo se ha utilizado, salvo rara excepción, la bibliografía original y se han rastreado las publicaciones desde la primera cita de cada taxón hasta las más recientes de todos los ámbitos que comprende el territorio estudiado, en el texto se incluyen sólo los rangos generales de distribución y no se pormenorizan citas concretas más que en casos puntuales.

Del mismo modo, dada la abundante bibliografía consultada para la elaboración de este catálogo, no se especifican más referencias que aquellas que la discusión o anotaciones concretas sobre las distintas interpretaciones de ciertos taxones han requerido y, por tanto, a pesar de haberse utilizado, como ya se ha apuntado, no las relativas a descripciones, citas, sinonimias o datos taxonómicos, que alargarían extraordinariamente el apartado correspondiente. Por la misma razón, excepto las más recientes o más generales (Spinola, 1843; 
Saunders, 1881, 1904; Alfken, 1927; Pérez, 1905; Diniz, 1960; Dufour, 1849; van der Zanden, 1961; Suárez \& Martínez, 1972; Pérez-Íñigo, 1980, 1984; Gayubo et al., 1990; González et al., 2002; Ortiz-Sánchez, 1990; Le Goff, 2003) o que se mencionan luego en la discusión, tampoco se pormenorizan todas las publicaciones en que se detallan citas ibéricas entre otras de territorios foráneos y tampoco las de Francia, Italia, etc. Sí se incluirá toda esa información, en su momento, en la monografía en la que se está trabajando en la actualidad, sobre la Fauna Ibérica de Megachilidae, como se hizo en la anterior sobre otras familias de abejas de la misma serie (Ornosa \& Ortiz-Sánchez, 2004), y cuyas características sí permiten ese volumen de referencias.

Con el término latino auctt., que aparece en el listado tras el nombre de varias especies, se alude a denominaciones y/o combinaciones empleadas por numerosos autores en un sentido diferente al establecido por el autor original. Igualmente, se emplea el término partim pues, aunque las sinonimias no lo son en parte, la diferencia entre sexos en apoideos ha hecho que la confusión en ocasiones sólo haya sido parcial, por lo que, sólo a título informativo, se señala.

Por último, es preciso puntualizar cierta situación anómala. Dusmet (1920) señalaba como españolas, de Cataluña, 15 especies de abejas de distintas familias (junto con la sospecha de otras muchas) de cuya primera y única cita (de ellas y de 252 más) Pérez (1895) dio el genérico "Barbarie", con la promesa de publicar más tarde las localidades, cosa que nunca hizo. Benoist (1924) coincidía o discrepaba en algunos de los casos (al ver material de "Megachile variscopa Pérez" de Argelia, que confirmaba, o de "Chalicodoma setulosa Pérez", que restringía a España sólo, por ejemplo). Ceballos (1956) recogió estas citas ibéricas, siguiendo el criterio de Dusmet, y van der Zanden (1989), sin aludir a Dusmet o autores posteriores, subrayaba lo mismo "....einige Tiere aus Spanien mit aufgenommen hat....".

Como esta situación es imposible de aclarar, porque no ha sido factible conseguir las notas manuscritas de Pérez y porque la duda de Dusmet (1920) iba más allá de los datos de localidad, en este estudio se opta por reseñarlo cuando proceda, además de en la distribución general que corresponda a cada especie y que incluirá también la cita original de Pérez (1895), pero con las debidas restricciones, si tales citas de Pérez (1895) no han podido ser confirmadas posteriormente con otras capturas.

\section{Resultados y discusión}

El total de especies que constituyen la fauna de Megachilidae del área mediterránea occidental sobrepasa las 430, con más de 500 subespecies, pertenecientes a 25 géneros y 5 tribus: Osmiini, Lithurgini, Megachilini, Dioxyini y Anthidiini. Los resultados que se exponen seguidamente tratan de la tribu Osmiini. Como se ha señalado ya, catálogos complementarios de éste constituirán una segunda y una tercera parte, que se publicarán en breve.

La fauna de Osmiini del área mediterránea occidental incluye 10 géneros, 33 subgéneros, 243 especies y 278 subespecies.

\section{Tribu Osmiini}

Género Chelostoma Latreille, 1809

Chelostoma Latreille, 1809. Gen. Crust. Ins., 4: 161

ESPECIE TIPO: Apis florisomnis Linnaeus, $1758=$ Apis maxillosa Linnaeus, 1767, por monotipia

Gyrodroma Thomson, 1872. Hym. Scand., 2: 259

ESPECIE TIPO: Heriades nigricornis Nylander, $1848=$ Gyrodroma nigricornis (Nylander, 1848), por designación de Cockerell, 1925

Distribución geográfica por el Holártico: Norteamérica, Eurasia, norte de África y noreste de la India, Birmania y Tailandia; de acuerdo con Michener (2000), existen 3 subgéneros en el territorio estudiado.

\section{Subgénero Chelostoma Latreille, 1809}

Distribución paleártica, aunque ha sido introducido en el estado de Nueva York, EE.UU. (Michener, 2000). Este autor le asignaba 27 especies en su área de expansión natural.

Chelostoma (Chelostoma) campanularum (Kirby, 1802)

Apis campanularum Kirby, 1802. Monogr. Apum Angliae, 2: 256 Apis florisomnis minima Christ, 1791. Naturg. der Insecten: 197 (non Poda, 1761)

Eriades florisomnis, auctt. (non Linnaeus, 1758)

Chelostoma florisomne, auctt. (non Linnaeus, 1758)

Especie distribuida, desde España en el sur, por toda Europa, excepto en las latitudes más altas del norte. Una referencia antigua (Maidl, 1922) de Argelia no parece haberse repetido posteriormente.

Dubitzky et al. (2005) la listan como una especie de Osmia Panzer, 1806.

Chelostoma (Chelostoma) carinula Pérez, 1895

Chelostoma carinula Pérez, 1895. Esp. nouv. Mellif. Barbarie: 19

Especie descrita originalmente de "Barbarie". Friese (1898) la refería de Argelia, como Eriades carinulus Pérez, 1895. 
Chelostoma (Chelostoma) confusum (Benoist, 1934)

Heriades confusa Benoist, 1934. Bull. Soc. entomol. France, 39: 158

Especie descrita originalmente de Argelia, aunque Rasmont et al (1995) incluían también Francia en su distribución.

Chelostoma (Chelostoma) distinctum (Stöckhert, 1929)

Eriades distinctum Stöckhert, 1929. Dt. Ent. Z.: 113

Heriades cantabrica Benoist, 1935. Bull. Soc. entomol. France, 40: 279

Distribución europea, en el sur llega desde España por el este hasta la Península Balcánica.

Dubitzky et al. (2005) la listan como una especie de Osmia.

Chelostoma (Chelostoma) edentulum Pérez, 1895

Chelostoma edentulum Pérez, 1895. Esp. nouv. Mellif. Barbarie: 20

Especie descrita originalmente de "Barbarie". Friese (1898) la refería de Argelia, como Eriades edentulus Pérez, 1895.

Chelostoma (Chelostoma) emarginatum (Nylander, 1856)

Heriades emarginata Nylander, 1856. Mém. Soc. Sci. nat. Cherbourg, 4: 109

Heriades appendiculata Morawitz, 1871. Horae Soc. entomol. Ross., 8: 209

Heriades angustata Chévrier, 1872. Mitt. schweiz. ent. Ges., 3 (10): 505

Heriades intermedia Chévrier, 1872. Mitt. schweiz. ent. Ges., 3 (10): 506

Chelostoma quadrifidum Kriechbaumer, 1879. Ent. Nachr., 5: 312

Chelostoma incertum Pérez, 1890. Act. Soc. Linn. Bordeaux, 44: 189 (non Radoszkowski, 1876)

Heriades ursina Benoist, 1935. Bull. Soc. entomol. France, 40: 280

Especie repartida por Europa meridional y central, Transcaucasia y norte de África.

Por otro lado, Chelostoma incertum Pérez, 1890, que fue referida por Ceballos (1956, tomado de Bofill, 1905) de España, Benoist (1928b) y Schwarz et al. (1996) la incluyeron como sinónima y, en cambio, fue considerada como especie válida por Rasmont et al. (1995) y Nobile \& Tomarchio (2000), autores, estos últimos, que le adjudicaron una distribución franco-sícula.

Chelostoma (Chelostoma) florisomne (Linnaeus, 1758) Apis florisomnis Linnaeus, 1758. Syst. Nat., ed. 10, 1: 577 Apis maxillosa Linnaeus, 1767. Syst. Nat., ed. 12, 1: 954 Chelostoma culmorum Lepeletier, 1841. Hist. Nat. Ins. Hym., 2: 408

Heriades parumcrinitus Alfken, 1932. Konowia, 11:113

Especie distribuida desde España en el sur, por toda Europa excepto las zonas altas del norte, norte de África y Cáucaso.
Dubitzky et al. (2005), al contrario de, por ejemplo, Ebmer (2003), la listan como una especie de Osmia.

Chelostoma (Chelostoma) grande (Nylander, 1852)

Heriades grandis Nylander, 1852. Notis. Saellsk. Faun. Flor. fenn. Förh., 2: 277

Especie distribuida desde Francia, por Europa central y meridional, hasta Grecia y Kosovo.

Chelostoma (Chelostoma) handlirschii Schletterer, 1889 Chelostoma handlirschii Schletterer, 1889. Zool. Jb. Abt. Syst., 4: 624

Heriades hebraea Benoist, 1935. Bull. Soc. entomol. France, 40: 280

Especie repartida por Francia, Italia, Grecia, Austria y Hungría, en Europa, Israel y Asia Menor.

Chelostoma (Chelostoma) mocsaryi Schletterer, 1889

Heriades gasperinii Schmiedeknecht, 1888. Annuar. Dalm., 5: 7 (no disponible)

Chelostoma mocsaryi Schletterer, 1889. Zool. Jb. Abt. Syst., 4: 622

Especie distribuida por Europa meridional excepto la Península Ibérica, el sur de Rusia y Asia Menor.

Chelostoma (Chelostoma) nasutum Pérez, 1895

Chelostoma nasutum Pérez, 1895. Esp. nouv. Mellif. Barbarie: 20

Heriades truncatus Friese, 1897. Ent. Nachr., 23: 193

Especie descrita de "Barbarie", que se conoce de Argelia.

Chelostoma (Chelostoma) proximum Schletterer, 1889

Chelostoma proxima Schletterer, 1889. Zool. Jb. Abt. Syst., 4: 663

Especie distribuida por el norte de África, Transcaspia y Asia Menor y, según Rasmont et al. (1995), hay una única cita de Francia.

Chelostoma (Chelostoma) styriacum Schwarz \& Gusenleitner, 1999

Chelostoma styriacum Schwarz \& Gusenleitner, 1999. Entomofauna, 20 (11): 211

Especie distribuida por Austria, Hungría y Bulgaria, en Europa central, y Grecia y la antigua Yugoslavia, en el área mediterránea.

Chelostoma (Chelostoma) ventrale Schletterer, 1889

Chelostoma ventrale Schletterer, 1889. Zool. Jb. Abt. Syst., 4: 624

Especie repartida por Europa central y meridional, territorio este último donde se conoce de los Pirineos orientales y Eslovenia, y por Turquía; fue citada de Madrid en España (Pérez-Íñigo, 1984) y referenciada del norte de África. 
Subgénero Foveosmia Warncke, 1991

Osmia (Foveosmia) Warncke, 1991. Linzer biol. Beitr., 23(1): 267 ESPECIE TIPO: Heriades foveolata Morawitz, 1868, por designación original

Subgénero establecido por Warncke (1991c) dentro del género Osmia, como un subgénero de especies de pequeño tamaño.

Chelostoma (Foveosmia) foveolatum (Morawitz, 1868)

Heriades foveolata Morawitz, 1868. Horae Soc. entomol. Ross., 5 [1867-1868]: 152

Especie con distribución por Europa, zonas cálidas del centro y Europa meridional, incluido el territorio mediterráneo septentrional, desde España hasta Turquía.

Subgénero Gyrodromella Michener, 1997

Gyrodroma Thomson, 1872. Stettin. ent. Ztg., 30: 259 (non Klug, 1807)

ESPECIE TIPO: Heriades nigricornis Nylander, $1848=$ Heriades rapunculi Lepeletier, 1841, por designación de Cockerell, 1925

Chelostoma (Gyrodromella) Michener, 1997. Scien. Pap. Nat. Hist. Mus. Univ. Kansas, 1: 27 (nomen novum para Gyrodroma Thomson, 1872)

ESPECIE TIPO: Heriades nigricornis Nylander, $1848=$ Heriades rapunculi Lepeletier, 1841, por monotipia y designación original

Subgénero de distribución paleártica, mejor conocido de Europa central y septentrional, de acuerdo con Griswold \& Michener (1998) y Michener (1997, 2000), autor éste, que le asignaba alrededor de 6 especies.

Chelostoma (Gyrodromella) rapunculi (Lepeletier, 1841) Apis fuliginosa Panzer, 1798. Fauna Ins. Germ. Initia: 56, n 16 (non Scopoli, 1770; nec Christ, 1791)

Heriades rapunculi Lepeletier, 1841. His. Nat. Ins. Hym., 2: 406

Heriades nigricornis Nylander, 1848. Notis. Saellsk. Faun.

Flor. fenn. Förh., 1, Adnot: 269

Chelostoma inerme Eversmann, 1852. Bull. Soc. Imp. Nat. Moscou, 25: 74 (non Zetterstedt, 1838)

Heriades casularum Chévrier, 1872. Mitt. schweiz. ent. Ges., 3 (10): 505

Osmia (Acanthosmia) platyodonta Cockerell, 1928. Ann. Mag.

Nat. Hist., 1 (10): 352

Osmia (Acanthosmia) archanensis Cockerell, 1928. Ann. Mag. Nat. Hist., 1 (10): 353

Especie distribuida por Siberia, el centro y el norte de Europa; por Francia, en el norte montañoso y en los Alpes; más rara en Europa meridional y Asia Menor; también se ha citado de Marruecos y de dos localidades españolas (Bofill, 1905; Ceballos, 1956; Pérez-Íñigo, 1984) y alguna de ellas, por lo menos, deberá ser confirmada.

Dubitzky et al. (2005), al contrario de, por ejemplo, van der Zanden (1990) o Ebmer (2003) la listan como una especie de Osmia.
Género Haetosmia Popov, 1952

Anthocopa (Haetosmia) Popov, 1952. Trudy Zool Inst. Akad. Nauk SSSR, Leningr., 10: 104.

ESPECIE TIPO: Osmia latipes Morawitz, $1875=$ Osmia brachyura Morawitz, 1875, por monotipia

Distribuido por las Islas Canarias, área mediterránea y África oriental, hasta Asia Central. Michener (2000) le asignaba 3 especies.

Haetosmia circumventa (Peters, 1974)

Osmia (Haetosmia) circumventa Peters, 1974. Senckenberg. biol., 55 (4-6): 297

Descrita de Canarias, esta especie se distribuye, además, por el Alto Atlas de Marruecos, en el norte de África, y en Sudán.

Género Heriades Spinola, 1808

Heriades Spinola, 1808. Ins. Ligur., 2: 7

ESPECIE TIPO: Apis truncorum Linnaeus, 1758, por designación de Latreille, 1810

Eriades Dalla Torre \& Friese, 1895. Ent. Nachr., 21: 69, enmienda injustificada

Trypetes Schenck, 1861. Jahrb. Ver. Naturk. Nassau, 14 [1859]: 32, 89 (non Schönherr, 1836)

ESPECIE TIPO: Apis truncorum Linnaeus, 1758, por monotipia Orientoheriades Gupta, 1987. Reichenbachia, 25 (15): 68

ESPECIE TIPO: Heriades orientalis Gupta, 1987, por designación original

Distribución holártica, etiópica y oriental. De acuerdo con Michener (2000), en el territorio considerado sólo aparece un subgénero.

Subgénero Heriades Spinola, 1808

Subgénero repartido desde África hasta el norte de Europa y hasta Asia Central, norte de la India y Seichelles por el este. Michener (2000) le asignaba 11 especies paleárticas.

Heriades (Heriades) crenulatus Nylander, 1856

Osmia punctatissima Lepeletier, 1841. His. Nat. Ins. Hym., 2: 329 (partim)

Heriades crenulata Nylander, 1856. Mém. Soc. Sci. nat. Cherbourg, 4: 111

Especie distribuida por Europa central y meridional, incluidas España y Portugal, y por el norte de África y Asia Menor.

Heriades (Heriades) labiatus Pérez, 1895

Heriades labiatus Pérez, 1895. Esp. nouv. Mellif. Barbarie: 17

Descrita de "Barbarie", aparece en Argelia y España.

Heriades (Heriades) rubicola Pérez, 1890

Heriades rubicola Pérez, 1890. Act. Soc. Linn. Bordeaux, 44: 190 
Heriades copeticus Morawitz, 1892. Horae Soc. entomol. Ross., 26: 149

Heriades crenulatus aurantifer Cockerell, 1931. The Entomolog., 64: 159

Especie distribuida en Europa central y meridional, incluida España, Marruecos en el norte de África y Transcaspia, en Asia.

Heriades (Heriades) truncorum (Linnaeus, 1758)

Apis truncorum Linnaeus, 1758. Syst. Nat., ed. 10, 1: 575 Apis xanthogastria Schrank, 1802. Fauna Boica, 2 (2): 381 Osmia punctatissima Lepeletier, 1841. His. Nat. Ins. Hym., 2: 329 (partim)

Heriades mordax Schletterer, 1889. Zool. Jb. Abt. Syst., 4: 661

Especie distribuida por toda Europa excepto el norte, por el área circunmediterránea y por el Cáucaso y Asia Menor. Osmia

Dubitzky et al. (2005) la listan como una especie de

Heriades (Heriades) wilmattae Cockerell, 1931

Heriades wilmattae Cockerell, 1931. The Entomolog., 64: 159 Heriades politulus Cockerell, 1931. The Entomolog., 64: 160

Especie endémica de Marruecos.

Género Hofferia Tkalcu, 1984

Hofferia Tkalcu, 1984. Annot. Zool. Bot., 158: 10

ESPECIE TIPO: Chelostoma schmiedeknechti Schletterer, 1889

= Hofferia schmiedeknechti (Schletterer, 1889), por designación original

Distribución circunmediterránea, incluyendo a Argelia, Marruecos, Turquía, países europeos mediterráneos, más otros de la Europa meridional como Rumanía y Bulgaria; Michener (2000) le asignaba entre 2 y 4 especies y no se reconocen subgéneros en él. La especie tipo ocupa el territorio más oriental, Rumania, Yugoslavia, y Asia Menor.

Hofferia mauritanica Lucas, 1846

Chelostoma mauritanica Lucas, 1846. Expl. sci. ent. Algerie, 3: 205

Eriades obtusus Friese, 1897. Ent. Nachr., 23: 193

Especie endémica de Argelia.

Género Hoplitis Klug, 1807

Hoplitis Klug, 1807. Mag. Insektenk., 6: 225

ESPECIE TIPO: Apis adunca Panzer, 1798 = Anthophora adunca Fabricius, 1804, por monotipia

Ctenosmia Thomson, 1872. Hym. Scand., 2: 233

ESPECIE TIPO: Apis adunca Panzer, 1798, por designación de Michener, 1941

Distribución holártica (Michener, 2000). En el territorio estudiado comprende 11 subgéneros.
Warncke (1988a, 1988b, 1991a, 1991b, 1991c, 1991d, 1991e, 1991f, 1991g, 1992b, por ejemplo) no consideraba los subgéneros de Hoplitis sino como subgéneros de Osmia Panzer, 1806.

Subgénero Alcidamea Cresson, 1864

Alcidamea Cresson, 1864. Proc. Ent. Soc. Philadelphia, 2: 385 ESPECIE TIPO: Alcidamea producta Cresson, 1864, por designación de Michener, 1941

Osmia (Acanthosmia) Thomson, 1872. Hym. Scand., 2: 233, 255 ESPECIE TIPO: Osmia montivaga Morawitz, $1872=$ Osmia mitis Thomson, 1872 (non Nylander, 1852), por designación de Sandhouse, 1943

Osmia (Liosmia) Thomson, 1872. Hym. Scand., 2: 233, sin especies; Friese, 1911. Das Tierreich, 28: 438

ESPECIE TIPO: Osmia claviventris Thomson, 1872, por designación de Michener, 1941

Osmia (Tridentosmia) Schmiedeknecht, 1885. Apidae Europaeae, 2 (11): 887

ESPECIE TIPO: Osmia tridentata Dufour y Perris, 1840, por designación de Michener, 1941

Autochelostoma Sladen, 1916. Canad. Entomol., 48: 270 ESPECIE TIPO: Alcidamea producta Cresson, $1864=$ Autochelostoma canadiensis Sladen, 1916, por monotipia

Heriades (Micreriades) Mavromoustakis, 1958. Ann. Mag. Nat. Hist., 13 (1): 444

ESPECIE TIPO: Heriades parnesica Mavromoustakis, 1958, por designación original

Distribución holártica; en el continente euroasiático presenta alrededor de 37 especies y es especialmente abundante en el área mediterránea (Michener, 2000).

Hoplitis (Alcidamea) acuticornis (Dufour \& Perris, 1840) Osmia acuticornis Dufour \& Perris, 1840. Ann. Soc. entomol. France, 9: 14

Osmia dentiventris Morawitz, $1877^{2}$. Horae Soc. entomol. Ross., 14: 45

Presenta una distribución geográfica por Europa meridional, incluidas la Península Ibérica, Canarias y Madeira - una subespecie no incluida aquí por tratarse de la región Macaronésica-, zonas cálidas de Europa central, norte de África, Oriente Próximo, Asia Menor, Cáucaso y Asia Central.

Existe discrepancia en la concepción de las poblaciones de esta especie entre van der Zanden (1985, 1988a, 1996) y Warncke (1991g). Ya el primero no incluía en su distribución el norte de África, área que asigna a Hoplitis (Alcidamea) camelina (Benoist, 1934) y con carácter

\footnotetext{
En relación con el año de publicación del volumen XIV de Horae Societatis Entomologicae Rossicae, Kerzhner (1984) señalaba 1877 para las páginas de este trabajo de Morawitz, aunque en la portada del volumen aparece su pertenencia a 1878, pero publicado en 1879 (Ornosa, 2001). A pesar de la discrepancia, se mantiene aquí 1877, para la entrega de las páginas del trabajo de Morawitz, pero haciendo constar en las referencias los tres años que aparecen en el volumen 14 para evitar confusiones. Algo parecido sucede con el volumen XX y de igual manera (Morawitz, 1886, 1887) se hace constar en las referencias.
} 
específico. Asimismo, van der Zanden (1988a, 1996) reconocía otra subespecie, Hoplitis (Alcidamea) acuticornis brunneipes (Peters, 1975), de Canarias y establecía Osmia acuticornis penelope Warncke, 1991 como sinónima de Hoplitis (Alcidamea) camelina. Aquí, sin menoscabo de una investigación posterior, se dejan, por el momento, con categoría subespecífica.

\section{Hoplitis (Alcidamea) acuticornis acuticornis (Dufour \&} Perris, 1840)

Osmia acuticornis Dufour \& Perris, 1840. Ann. Soc. entomol. France, 9: 14

Subespecie que se reparte por Europa meridional, incluidas Creta y Chipre, zonas cálidas de Europa central, Oriente Próximo, Argelia en el norte de África, Asia Menor, Cáucaso y Kopet-Dagh en Asia Central.

Hoplitis (Alcidamea) acuticornis camelina (Benoist, 1934)

Osmia camelina Benoist, 1934. Bull. Soc. entomol. France, 39: 106

Osmia acuticornis penelope Warncke, 1991. Linzer biol. Beitr, 23(2): 724

Subespecie distribuida por Marruecos y Túnez. Van der Zanden (1985, 1988a, 1996), como se ha indicado antes, le asignaba rango específico.

Hoplitis (Alcidamea) acuticornis hispanica (Schmiedeknecht, 1885)

Osmia hispanica Schmiedeknecht, 1885. Apidae Europaeae, 2 (11): 915

Subespecie endémica de España.

Hoplitis (Alcidamea) alectoris (Warncke, 1991)

Osmia alectoris Warncke, 1991. Linzer biol. Beitr., 23 (2): 727 Osmia freygessneri Friese, 1899. Ent. Nachr., 25: 26 (non Schletterer, 1889)

Especie distribuida por Argelia y Marruecos.

Hoplitis (Alcidamea) ciliaris (Pérez, 1902)

Osmia ciliaris Pérez, 1902. Proc. ver. Soc. Linn. Bordeaux, 57: 65 ?Osmia grinincensis Benoist, 1969. Bull. Soc. Scienc. Nat. Maroc, 74: 244

Especie distribuida en el sur de Europa, citada de Francia, la antigua Yugoslavia y Grecia.

Hoplitis (Alcidamea) claviventris (Thomson, 1872)

Osmia punctatissima Schenck, 1851 Jahrb. Ver. Naturk. Nassau, 7: 68 (no disponible)

Osmia interrupta Schenck, 1861. Jahrb. Ver. Naturk. Nassau, 14 [1859]: 341 (non Latreille, 1811)

Osmia claviventris Thomson, 1872. Hym. Scand., 2: 254

Osmia foveolata Schenck, 1873. Berl. ent. Z., 17: 249 (non Morawitz, 1868)

Hoplitis leucomelana, auctt. (non Kirby, 1802)

Osmia leucomelana, auctt. (non Kirby, 1802)
Especie distribuida por Eurasia, desde el norte de Siberia, a través de Europa central y meridional, hasta el sur, por el norte del área mediterránea, las islas mediterráneas y desde la Península Ibérica a Turquía y el Cáucaso.

Hoplitis (Alcidamea) claviventris claviventris (Thomson, 1872)

Osmia claviventris Thomson, 1872. Hym. Scand., 2: 254

Subespecie europea, que llega en el sur hasta España y Portugal, se reparte por el área mediterránea y se extiende al Cáucaso.

Hoplitis (Alcidamea) claviventris columba (Warncke, 1991)

Osmia claviventris columba Warncke, 1991. Linzer biol. Beitr., 23 (2): 717

Subspecie endémica de España.

\section{Hoplitis (Alcidamea) curtula (Pérez, 1895)}

Osmia curtula Pérez, 1895. Esp. nouv. Mellif. Barbarie: 16 Osmia bofilli Pérez, 1905. Butll. Inst. Catalana Hist. Nat., 6: 82

Especie citada de "Barbarie" (Pérez, 1895), sur de Francia, España y Turquía. Van der Zanden (1984, 1988a, 1989) se cuestionaba alguna de las citas españolas (Pérez-Íñigo, 1980).

\section{Hoplitis (Alcidamea) grandiscapa (Pérez, 1895)}

Osmia grandiscapa Pérez, 1895. Esp. nouv. Mellif. Barbarie: 16

Citada originalmente de "Barbarie", esta especie se conoce de Argelia, Marruecos, entre 1.900-2.500 m, y Cerdeña.

\section{Hoplitis (Alcidamea) illyrica (Noskiewicz, 1926)}

Osmia illyrica Noskiewicz, 1926. Polski. Pismo. Entomol., 4 [1925]: 234

Descrita de Dalmacia, en Croacia, se distribuye además en el área mediterránea oriental por Albania, Rodas en Grecia, y Sicilia en Italia. Para Mavromoustakis (1960), Tkalcu (1974b) y Nobile \& Tomarchio (2000), considerada como Heriades (Micreriades).

Hoplitis (Alcidamea) lamina (Pérez, 1895)

Osmia lamina Pérez, 1895. Esp. nouv. Mellif. Barbarie: 15

Osmia triloba Benoist, 1928. Bull. Soc. Scienc. Nat. Maroc, 8: 214

Especie descrita de "Barbarie", se conoce del Gran Atlas en Marruecos.

\section{Hoplitis (Alcidamea) leucomelana (Kirby, 1802)}

Apis leucomelana Kirby, 1802. Monogr. Apum Angliae, 2: 260 Apis caulicola Schrank, 1802. Fauna Boica, 2 (2): 383

Apis zonata Graventhorst, 1807. Vergl. Übers. Zool. Syst.: 284 (non Linnaeus, 1758) 
Osmia parvula Dufour \& Perris, 1840. Ann. Soc. entomol. France, 9: 8

Heriades bidenticulata Costa, 1863. Atti. Accad. Sc. fis. mat. Napoli, 1 (2): 46

Especie paleártica occidental, distribuida por Argelia en el norte de África, zonas bajas del norte de Europa, Europa central y meridional, incluida la Península Ibérica, Francia, Italia y Córcega, y por Turquía, llegando por el este hasta Asia Central.

Hoplitis (Alcidamea) mitis (Nylander, 1852)

Osmia mitis Nylander, 1852. Notis. Saellsk. Faun. Flor. fenn. Förh., 2: 272

Osmia montivaga Morawitz, 1872. Verh. zool.-bot. Ges. Wien., 22: 361

Osmia laevifrons Pérez, 1879. Act. Soc. Linn. Bordeaux, 33: 190 (non Morawitz, 1872)

Especie paleártica occidental, repartida por Europa central y meridional, donde se conoce de España, Francia y Grecia, y en el este Asia Central.

Hoplitis (Alcidamea) mitis granadae Tkalcu, 1984

Hoplitis (Acanthosmia) mitis granadae Tkalcu, 1984. Bull. Soc. Entomol. Mulhouse: 8

Subespecie endémica de España, de Sierra Nevada.

Hoplitis (Alcidamea) mitis mitis (Nylander, 1852)

Osmia mitis Nylander, 1852. Notis. Saellsk. Faun. Flor. fenn. Förh., 2: 272

Subespecie que se reparte por Europa central y meridional, desde España y Francia hasta Grecia, y que por el este aparece en Asia Central.

Warncke (1991g; p. 727), en la frase que incluye "desde el NE de España” presumiblemente se confunde al referir la cita de $O$. laevifrons Pérez, 1879, que Pérez daba para el Pirineo, pero el Pirineo francés, ya que dicho trabajo es sobre fauna de Francia y no de España.

Hoplitis (Alcidamea) praestans (Morawitz, 1893)

Osmia praestans Morawitz, 1893. Horae Soc. entomol. Ross., 28: 31

Osmia lineola Pérez, 1895. Esp. nouv. Mellif. Barbarie: 16

Especie distribuida por Europa, desde España y sur de Francia hasta Hungría y Grecia por el este, Turquía, el norte de África (Marruecos, Túnez, Argelia y Egipto), Israel y Uzbekistán.

Hoplitis (Alcidamea) pungens (Benoist, 1928)

Osmia pungens Benoist, 1928. Bull. Soc. Scienc. Nat. Maroc, 8: 214

Especie endémica de Marruecos, del Gran Atlas.

Hoplitis (Alcidamea) tenuispina (Alfken, 1936)

Osmia tenuispina Alfken, 1936. Boll. Ist. Ent. Univ. Bologna, 9: 107
Especie distribuida en Europa central, por Hungría, Chequia, Eslovaquia y Austria, y meridional, por Italia, Grecia y la antigua Yugoslavia, así como en Turquía.

\section{Hoplitis (Alcidamea) tricolor (Saunders, 1908)}

Osmia tricolor Saunders, 1908. Trans. ent. Soc. London: 249 Osmia crosi Benoist, 1929. Bull. Soc. entomol. France: 96

Especie conocida de Argelia, Marruecos y Jordania.

Van der Zanden (1988a) incluía esta especie como perteneciente a Anthocopa, en su subgénero nominal. Por otro lado, para van der Zanden (1991), Osmia crosi de Argelia era una especie válida, que más tarde estableció como sinónima (van der Zanden, 1995). Para Warncke (1992a) era sinónima de Osmia derasa Pérez, 1895.

Hoplitis (Alcidamea) tridentata (Dufour \& Perris, 1840) Osmia tridentata Dufour \& Perris, 1840. Ann. Soc. entomol. France, 9: 10

Especie paleártica occidental, distribuida por Argelia y Marruecos en el norte de África, Europa central y sur, incluidas España y Francia, Turquía, el Cáucaso y el Turkestán, en Asia Central.

Hoplitis (Alcidamea) tridentata melanoleuca (Benoist, 1934)

Osmia melanoleuca Benoist, 1934. Bull. Soc. entomol. France, 39: 108

Hoplitis (Tridentosmia) tridentata asensioi Tkalcu, 1975. Arch. Inst. Aclim. Almeria, 20: 17

Subespecie íbero-magrebí, de España, Marruecos y Argelia, y de Egipto.

Hoplitis (Alcidamea) tridentata tridentata (Dufour \& Perris, 1840)

Osmia tridentata Dufour \& Perris, 1840. Ann. Soc. entomol. France, 9: 10

Subspecie distribuida por Europa central, Turquía occidental e Irán.

Hoplitis (Alcidamea) villiersi (Benoist, 1950)

Osmia villiersi Benoist, 1950. Bull. Inst. Fr. d'Afr. Noire: 942

Osmia strepera Warncke, 1991. Entomofauna, 12: 17

Especie norteafricana, repartida a través de Marruecos, Argelia, Túnez y Mauritania.

De acuerdo con Michener (2000), Tridentosmia es sinónima de Alcidamea y van der Zanden (1988b) señalaba que Osmia villiersi pertenece al subgénero Tridentosmia. Van der Zanden (1988b) la incluía en Osmia y no en Hoplitis.

Subgénero Annosmia Warncke, 1991

Osmia (Annosmia) Warncke, 1991. Linzer biol. Beitr., 23 (1): 307 ESPECIE TIPO: Osmia annulata Latreille, 1811, por designación original 
Distribuido por el área mediterránea hasta Asia Central, Beluchistán (en Pakistán) y, por el sur, llega hasta el norte de Sudán. Michener (2000) le asignaba entre 27 y 31 especies.

Rasmont et al. (1995) no consideran a Annosmia como un subgénero independiente.

Hoplitis (Annosmia) annulata (Latreille, 1811)

Osmia annulata Latreille, 1811. Encycl. méthod. Ins., 8: 587 Osmia pruinosa De Stefani, 1887. Nat. Sicil., 6: 112

Especie distribuida en España, de donde fue descrito el tipo, Portugal, Francia, Sicilia y el norte de África, desde Marruecos a Túnez, en su forma nominal. Aparte, existen otras subespecies, no incluidas aquí, que se reparten por Córcega, Creta, Grecia, Chipre, Turquía, Palestina e Israel, hasta el Cáucaso.

Hoplitis (Annosmia) bassana (Warncke, 1991)

Osmia bassana Warncke, 1991. Linzer biol. Beitr., 23 (1): 313

Especie distribuida en Marruecos y Argelia.

Hoplitis (Annosmia) gusenleitneri (Warncke, 1991)

Osmia gusenleitneri Warncke, 1991. Linzer biol. Beitr., 23(1): 323

Especie distribuida en Marruecos.

Hoplitis (Annosmia) hierichonica (Mavromoustakis, 1949) Osmia hierichonica Mavromoustakis, 1949. Eos, 25: 292

Especie distribuida en Israel, de donde es la forma nominal, y en el norte de África.

Hoplitis (Annosmia) hierichonica wolfi (Warncke, 1991) Osmia hierichonica wolfi Warncke, 1991. Linzer biol. Beitr. 23 (1): 316

Subespecie distribuida en Marruecos y Túnez.

Hoplitis (Annosmia) marchali (Pérez, 1902)

Osmia marchali Pérez, 1902. Proc. ver. Soc. Linn. Bordeaux, 57: 67

Especie mediterránea occidental, distribuida por España, Sicilia en Italia, Córcega en Francia, y Marruecos, Argelia y Túnez, en el norte de África.

Hoplitis (Annosmia) nisa (Warncke, 1991)

Osmia nisa Warncke, 1991. Linzer biol. Beitr., 23 (1): 329

Hoplitis (Hoplitis) speculumoides van der Zanden, 1991. Linzer. biol. Beitr., 23 (1): 350

Especie distribuida en Marruecos y Argelia.

Hoplitis (Annosmia) ochruros (Warncke, 1991)

Osmia ochruros Warncke, 1991. Linzer biol. Beitr., 23 (1): 322

Especie distribuida en Marruecos, Argelia y Túnez.
Hoplitis (Annosmia) speculum (Benoist, 1934)

Osmia speculum Benoist, 1934. Bull. Soc. entomol. France, 39: 106

Osmia pseudospeculum Benoist, 1934. Bull. Soc. entomol. France, 39: 107

Especie distribuida en Marruecos y Argelia.

Hoplitis (Annosmia) tkalcuella Le Goff, 2003

Hoplitis (Annosmia) tkalcuella Le Goff, 2003. Bull. Soc. entomol. France, 108 (1): 67

Especie distribuida en España.

Hoplitis (Annosmia) tunica (Warncke, 1991)

Osmia tunica Warncke, 1991. Linzer biol. Beitr., 23 (1): 323

Especie distribuida en Túnez.

Hoplitis (Annosmia) zonalis (Pérez, 1895)

Osmia zonalis Pérez, 1895. Esp. nouv. Mellif. Barbarie: 14 Osmia undulata Pérez, 1902 Pérez, 1902. Proc. ver. Soc. Linn. Bordeaux, 57: 66

Osmia taprurensis Benoist, 1929. Bull. Soc. entomol. France: 98

Descrita de "Barbarie", la forma nominal se distribuye por Marruecos, Argelia y Túnez; también existe otra subespecie de Israel.

Por otro lado, para van der Zanden (1985, 1988a) tanto Osmia undulata como Osmia taprurensis son especies válidas.

Subgénero Anthocopa Lepeletier \& Serville, 1825

Anthocopa Lepeletier \& Serville, 1825. Encycl. Mèthod. Hist. Nat. Ins., 10: 314

ESPECIE TIPO: Apis papaveris Latreille, $1799=$ Anthophora papaveris Lepeletier \& Serville, 1825, por monotipia

Phyllotoma Duméril, 1860. Mem. Acad. Sci. Inst. Imp. France., 31: 842 (non Leach, 1819; nec Fallen, 1829) ESPECIE TIPO: Apis papaveris Latreille, 1799, por designación de Michener, 1941

Pseudosmia Radoszkowski, 1872 Horae Soc. entomol. Ross., 8: XVIII. sin especies; Radoszkowski, 1874. Bull. Soc. Imp. Nat. Moscou, 48 (1) : 152

ESPECIE TIPO: Megachile cristata Fonscolombe, 1846 (non Dufour, 1841) $=$ Anthocopa cristata $($ Fonscolombe, 1846) $=$ Anthocopa cristatula van der Zanden, 1990, por designación de Cockerell, 1922

Pseudo-osmia Radoszkowski, 1873. Bull. Soc. Imp. Nat. Moscou, 46 (2): 137, enmienda injustificada

Pseudoosmia Radoszkowski, 1874. Bull. Soc. Imp. Nat. Moscou, 48 (1): 152, enmienda injustificada

Osmia (Arctosmia) Schmiedeknecht, 1885. Apidae Europaeae, 2 (11): 887

ESPECIE TIPO: Megachile villosa Schenck, $1853=$ Osmia platycera Gerstaecker, 1869, (non Apis villosa Fabricius, 1775), por monotipia

Osmia (Furcosmia) Schmiedeknecht, 1885. Apidae Europaeae., 2 (11): 888

ESPECIE TIPO: Apis papaveris Latreille, 1799, por designación de Cockerell, 1922 
Pseudocosmia Radoszkowski, 1886. Horae Soc. entomol. Ross., 20 (1885-1887): 14, enmienda injustificada Osmia (Lithosmia) Alfken, 1935. Veröff. dt. Kolon. u. ÜberseeMus. Bremen, 1: 188

ESPECIE TIPO: Megachile villosa Schenck, $1853=$ Osmia platycera Gerstaecker, 1869 (non Apis villosa Fabricius, 1775 ) por designación de Sandhouse, 1943

Osmia (Glossosmia) Michener, 1943. Ann. Entomol. Soc. Am., 36: 84

ESPECIE TIPO: Osmia singularis Morawitz, 1875, por designación original

Distribución paleártica y etiópica, especialmente abundante en el área mediterránea; Michener (2000) le asignaba entre 57 y 62 especies.

En este trabajo, por el momento y sin menoscabo de investigaciones posteriores que aclaren definitivamente la cuestión, de acuerdo con Michener (2000), se considera a Anthocopa como un subgénero de Hoplitis; no obstante, otros puntos de vista pueden encontrarse, por ejemplo, en van der Zanden (1994a, 1998), Rasmont et al (1995), Schwarz et al (1996), Banaszak (2000) o Standfuss et al. (2003).

Hoplitis (Anthocopa) alba (van der Zanden, 1994)

Anthocopa (Anthocopa) alba van der Zanden, 1994. Linzer. Biol. Beitr., 26 (2): 1117

Especie endémica de Marruecos.

Hoplitis (Anthocopa) antigae (Pérez, 1895)

Osmia antigae Pérez, 1895. Esp. nouv. Mellif. Barbarie: 13

Distribución íbero-magrebí.

Descrita de "Barbarie", Benoist (1924) corregía sobre el material de Pérez la cita original y restringía la distribución a España "únicamente"; más tarde (Benoist, 1926), establecía una nueva variedad de Argelia, "laevior" que van der Zanden (1988b; p. 62) consideró como subespecie al estudiar, además, material del Museo de París proveniente de España ("El Solidad") y Marruecos (Marrakech).

Hoplitis (Anthocopa) antigae antigae (Pérez, 1895) Osmia antigae Pérez, 1895. Esp. nouv. Mellif. Barbarie: 13

Subespecie endémica de España.

Hoplitis (Anthocopa) antigae laevior (Benoist, 1926)

Osmia antigae var. laevior Benoist, 19263. Ann. Soc. entomol. France, 95: 210

Subespecie distribuida en España y, en el norte de África, en Argelia y Marruecos.

\footnotetext{
Rasmont et al. (1995) incluían como sinonimia a "Anthocopa contigua Pérez (nomen nudum)", que no se ha podido localizar al no constar otros datos en la referencia.
}

Hoplitis (Anthocopa) ayardi (Benoist, 1928)

Osmia ayardi Benoist, 1928. Bull. Soc. Scienc. Nat. Maroc, 8: 213

Especie endémica de Marruecos.

Hoplitis (Anthocopa) barbigera (Benoist, 1950)

Osmia barbigera Benoist, 1950. Bull. Soc. Scienc.Nat. Maroc, 30: 187

Especie endémica de Marruecos.

Hoplitis (Anthocopa) bisulca (Gerstaecker, 1869)

Osmia bisulca Gerstaecker, 1869. Stettin. ent. Ztg., 30: 344

Osmia lanosa Pérez, 1879. Act. Soc. Linn. Bordeaux, 33: 194

Especie distribuida en Europa meridional, incluida España, y Argelia, en el norte de África, Palestina en el Oriente Próximo y Uzbekistán en Asia Central.

Por otro lado, Osmia lanosa Pérez, 1879, de Argelia y Francia meridional, para Baker (1996) era una especie válida, que incluía como Anthocopa (Anthocopa) lanosa (Pérez, 1879).

Hoplitis (Anthocopa) brevifurca (Benoist, 1934)

Osmia brevifurca Benoist, 1934 Bull. Soc. entomol. France, 39: 159

Especie endémica de Marruecos.

Hoplitis (Anthocopa) bubulca (van der Zanden, 1994) Anthocopa (Anthocopa) bubulca van der Zanden, 1994. Linzer. Biol. Beitr., 26 (2): 1119

Especie endémica de Marruecos.

Hoplitis (Anthocopa) cristatula (van der Zanden, 1990) Megachile cristata Fonscolombe, 1846. Ann. Soc. entomol. France, 4: 46 (non Dufour, 1841)

Anthocopa cristatula van der Zanden, 1990. Reichenbachia, 28 (9): 51

Especie distribuida en el sur de Europa, en Francia, España e Italia.

Hoplitis (Anthocopa) dalmatica (Morawitz, 1871)

Osmia dalmatica Morawitz, 1871. Horae Soc. entomol. Ross., 8: 207

Especie distribuida en el sur de Europa, en Francia, Italia y Croacia, y en Suiza y Hungría.

Hoplitis (Anthocopa) diabolica (Benoist, 1934)

Osmia diabolica Benoist, 1934 Bull. Soc. entomol. France, 39: 159

Especie endémica de Argelia.

Hoplitis (Anthocopa) grumii (Morawitz, 1894)

Osmia grumii Morawitz, 1894. Horae Soc. entomol. Ross., 28: 28 Osmia jagnobensis Morawitz, 1894. Horae Soc. entomol. Ross., 28: 32

Conocida de España, Turquía y Turkestán. 
Hoplitis (Anthocopa) ilamana (van der Zanden, 1994)

Anthocopa (Anthocopa) ilamana van der Zanden, 1994. Linzer. Biol. Beitr., 26 (2): 1118

Especie distribuida por Argelia y Marruecos.

Hoplitis (Anthocopa) jakovlevi (Radoszkowski, 1874) Pseudosmia jakovlevi Radoszkowski, 1874. Bull. Soc. Imp. Nat. Moscou,. 48 (1): 155

Osmia serrilabris Morawitz, 1875. En: Fedtschenko, Izv. Imp. Obshch. Ljubit. Estest. Antrop. Etnog., 19: 91

Especie descrita de Astracán, en Rusia, se reparte también por el Turkestán, Irán, Francia en el sur de Europa y el norte de África.

La combinación actual y la consideración de Osmia serrilabris como sinónima se deben a van der Zanden (1996).

Por otro lado, un sinónimo de Osmia serrilabris, "Osmia quadridentata (Fonscolombe in Pérez, 1879)", que aparecía así en Rasmont et al. (1995) y como “ $A$. quadridentata Pérez, 1879” en van der Zanden (1996), no coincide con ninguna de las especies descritas en 1879 ni con ninguna de las referencias que se hayan podido comprobar en la literatura. Con categoría subespecífica la situaba van der Zanden (1988a) como "Anthocopa (Anthocopa) serrilabris quadridentata (Pérez, 1879) Süd Europa, Nord Afrika”. Pérez (1879; p. 191) sí incluía Osmia quadridentata, pero no como una nueva especie que describiera él sino como "Osmia quadridentata Boyer", que trataba y citaba de Francia oriental. Es más tarde (Pérez, 1890; p. 159) cuando aparece en el listado de especies de ese trabajo, efectivamente como "Osmia quadridentata Fonscol.", esta vez de Toulouse. No obstante, Boyer de Fonscolombe murió en $1853 \mathrm{y}$, de acuerdo con el "Index Animalium de Sherborn (especies descritas entre 1801 y 1850)", no figura ninguna descrita con la denominación de "quadridentata".

Hoplitis (Anthocopa) longispina (Pérez, 1895)

Osmia longispina Pérez, 1895. Esp. nouv. Mellif. Barbarie: 14 Osmia gigas Friese, 1899. Ent. Nachr., 25: 62

Descrita de "Barbarie", se distribuye por el norte de África y Francia.

Hoplitis (Anthocopa) longispina longispina (Pérez, 1895)

Osmia longispina Pérez, 1895. Esp. nouv. Mellif. Barbarie: 14

Subespecie distribuida por Argelia y Egipto, en el norte de África, y por Francia.

Hoplitis (Anthocopa) longispina vogti (Friese, 1911) Osmia vogti Friese, 1911. Archiv. f. Naturg., 77 I (2): 135, 143. Subespecie endémica de Túnez.
Hoplitis (Anthocopa) maghrebensis (van der Zanden, 1992)

Anthocopa (Anthocopa) maghrebensis van der Zanden, 1992. Reichenbachia, 29 (12): 67

Especie endémica de Marruecos.

Hoplitis (Anthocopa) maroccana (van der Zanden, 1998). Anthocopa (Anthocopa) maroccana van der Zanden, 1998. Linzer biol. Beitr., 30 (2): 526

Especie endémica de Marruecos.

Hoplitis (Anthocopa) mocsaryi (Friese, 1895)

Osmia mocsaryi Friese, 1895. Ent. Nachr., 21: 133

Especie distribuida por Rumanía, Polonia y Austria en Europa central y por Francia y España en Europa meridional, así como en Turquía.

Hoplitis (Anthocopa) nasoincisa (Ferton, 1914)

Osmia nasoincisa Ferton, 1914. Ann. Soc. entomol. France, 83: 83

Especie endémica de Argelia.

Hoplitis (Anthocopa) papaveris (Latreille, 1799)

Apis papaveris Latreille, 1799. Bull. Sci. Soc. philom. Paris, 2: 33 Osmia hyalinipennis Lepeletier, 1841. His. Nat. Ins. Hym., 2: 329 Anthocopa pacifica, auctt. (non Panzer, 1798)

Especie distribuida por Europa central, desde Francia, y el Cáucaso.

Van der Zanden (1984) la citaba de España, lo que entonces daba verosimilitud a otras citas dudosas antiguas, o referencias posteriores a ellas, de la Península Ibérica (Bofill, 1905; Maidl, 1922; Ceballos, 1956; Diniz, 1960; Vergés, 1964). No obstante, más tarde, van der Zanden (1988a) sólo incluía como distribución de esta especie la de Europa central, prescindiendo de las demás.

Hoplitis (Anthocopa) perezi (Ferton, 1894)

Osmia perezi Ferton, 1894. Act. Soc. Linn. Bordeaux, 47: 205 Osmia convolvuli Ducke, 1899. Ent. Nachr., 25: 214

Osmia papaveris convolvuli Ducke, 1899. Ent. Nachr., 25: 214

Especie mediterránea, de Francia, Grecia, Marruecos y Argelia, referenciada también de España (Ceballos, 1956) y de Afganistán.

\section{Hoplitis (Anthocopa) pulchella (Pérez, 1895)}

Osmia pulchella Pérez, 1895. Esp. nouv. Mellif. Barbarie: 15 Osmia lativentris Friese, 1899. Ent. Nachr., 25: 27

Osmia lativentris var. albiscopa Friese, 1899. Ent. Nachr., 25: 27

Especie descrita de "Barbarie", ampliamente repartida por el norte de África, en Marruecos, Argelia, Túnez Libia y Egipto, Jordania en Oriente Próximo y España. 
Hoplitis (Anthocopa) quarzazati (van der Zanden, 1998) Anthocopa (Anthocopa) quarzazati van der Zanden, 1998. Linzer biol. Beitr., 30 (2): 526

Especie endémica de Marruecos.

Hoplitis (Anthocopa) rubricrus (Friese, 1899)

Osmia rubricrus Friese, 1899. Ent. Nachr., 25: 25

Especie del norte de África, Marruecos y Argelia, incluido el Sahara.

Hoplitis (Anthocopa) rugidorsis (Pérez, 1895)

Osmia rugidorsis Pérez, 1895. Esp. nouv. Mellif. Barbarie: 14 Anthocopa fasciculata Alfken, 1932. Mitt. D. Ent. Ges., 3: 116124.

Descrita de "Barbarie", se localiza en Argelia, en el norte de África, y en Cerdeña e Italia continental.

Hoplitis (Anthocopa) saundersi (Vachal, 1891)

Osmia saundersi Vachal, 1891. Rev. Ent., 10: 66

Especie distribuida por Argelia, en el norte de África, y Montenegro, en el sur de Europa.

Hoplitis (Anthocopa) simula (Gribodo, 1894)

Osmia simula Gribodo, 1894. Boll. Soc. entomol. Ital., 26: 287 Osmia florigera Ferton, 1914. Ann. Soc. entomol. France, 83: 84

Especie distribuida en el norte de África por Marruecos, Argelia y Túnez.

Hoplitis (Anthocopa) sordida (Benoist, 1929)

Osmia sordida Benoist, 1929. Bull. Soc. entomol. France: 99 Osmia bodenheimeri Mavromoustakis, 1949. Eos, 25: 289

Especie descrita de Siria y que posteriormente van der Zanden (1988a) referenciaba del norte de África.

Hoplitis (Anthocopa) ursina (Friese, 1921)

Osmia ursina Friese, 1921. D. Ent. Z. 1920: 49

Osmia armata Benoist, 1927. Bull. Soc. sci. nat. Maroc, 7: 270

Especie distribuida en el norte de África por Argelia y Túnez.

Hoplitis (Anthocopa) villosa (Schenck, 1853)

Megachile villosa Schenck, 1853. Jahrb. Ver. Naturk. Nassau, 9: 178 (non Fabricius, 1775; nec Henschel, 1888)

Osmia platycera Gerstaecker, 1869. Stettin. ent. Ztg., 30: 338

Su distribución comprende el norte de Europa y sobre todo áreas montañosas de Europa central y meridional, de España, Francia, Italia, Croacia, Albania y el Líbano; de las referencias y citas de España (Maidl, 1922; Ceballos, 1956, Pérez-Íñigo, 1984, Tkalcu, 2000, Ebmer, 2003) las más meridionales, fuera de Pirineos y la Cordillera Cantábrica, precisan confirmación.
Hoplitis (Anthocopa) zaianorum (Benoist, 1927)

Osmia zaianorum Benoist, 1927. Bull. Soc. sci. nat. Maroc, 7: 170

Especie endémica de Marruecos.

Subgénero Bytinskia Mavromoustakis, 1954

Bytinskia Mavromoustakis, 1954. Bull.Research Counc. Israel, 4: 269

ESPECIE TIPO: Bytinskia erythrogastra Mavromoustakis, 1954, por designación original

Distribución mediterránea, por Turquía, Marruecos y Túnez, en Oriente Próximo por Israel y Jordania y por Kenia en la región etiópica. Michener (2000) le asignaba cuatro especies.

Hoplitis (Bytinskia) erythrogastra (Mavromoustakis, 1954) Bytinskia erythrogastra Mavromoustakis, 1954. Bull.Research Counc. Israel, 4: 269

Especie distribuida por el norte de África, en Marruecos y Túnez, y Oriente Próximo, Jordania e Israel.

Subgénero Exanthocopa Tkalcu, 1993

Hoplitis (Exanthocopa) Tkalcu, 1993. Bull. Soc. Entomol. Mulhouse: 55

ESPECIE TIPO: Osmia oxypyga Benoist, 1927, por monotipia y designación original

Subgénero conocido de Marruecos y Argelia y, según Michener (2000), representado por una sola especie.

Hoplitis (Exanthocopa) oxypyga (Benoist, 1927)

Osmia oxypyga Benoist, 1927. Bull. Soc. sci. nat. Maroc, 7: 169

Especie distribuida en Marruecos y Argelia.

Subgénero Hoplitis Klug, 1807

Distribución paleártica, desde Europa Central al norte de África y desde Canarias, España e Islas Británicas hasta Asia Central, aunque, según Michener (2000), que le asigna 43 especies, alguna de las especies está establecida en EE.UU.

\section{Hoplitis (Hoplitis) adunca (Panzer, 1798)} Apis adunca Panzer, 1798. Fauna Ins. Germ. Initia: 56, 5

Especie paleártica occidental. En Europa aparece desde el norte hasta España y, por el área mediterránea, en el norte de África y en Asia Menor, Transcaspia, Cáucaso y Turkestán. Para distintos autores, en España y en el norte de África existe en la subespecie contraria (Tkalcu, 1974a, 1975b; van der Zanden, 1988a).

Hay que tener en cuenta que Tkalcu (1974a, 1975b), van der Zanden (1988a) y Rasmont et al. (1995) tienen opiniones distintas en la interpretación de las subespecies 
de Hoplitis adunca y las sinonimias que incluyen. Tkalcu (1974a y 1975b) estudiaba los tipos e incluía a Osmia spinolae Lepeletier, 1841 y Osmia marginella Lepeletier, 1841 como sinónimas de la subespecie nominal; en cambio van der Zanden (1988a) y Rasmont et al (1995) las situaban en Hoplitis adunca contraria Tkalcu, 1974. Warncke (1992a) no reconocía a Hoplitis adunca contraria, pero señalaba (p. 116) que "los animales del sur de Europa y del norte de África tienen el pelo más claro”.

Hoplitis (Hoplitis) adunca adunca (Panzer, 1798)

Apis adunca Panzer, 1798. Fauna Ins. Germ. Initia: 56, 5 Osmia spinolae Lepeletier, 1841. His. Nat. Ins. Hym., 2: 328 (non Schenck, 1851)

Osmia marginella Lepeletier, 1841. His. Nat. Ins. Hym., 2: 320 (partim)

Subespecie repartida por Europa hasta el norte, Asia Menor, el Cáucaso y Transcaspia.

Hoplitis (Hoplitis) adunca contraria Tkalcu, 1974

Hoplitis (Hoplitis) adunca contraria Tkalcu, 1974. Beitr. Ent., Berlin, 24 (5/8): 329

Osmia aduncoides Strand, 1910. Ent. Zeit., 24: 216 (partim)

Subespecie de la Península Ibérica y del norte de África, desde Marruecos y Argelia hasta Libia.

Hoplitis (Hoplitis) anthocopoides (Schenck, 1853)

Osmia spinolae Schenck, 1851. Jahrb. Ver. Naturk. Nassau, 7: 68, 우 (non Lepeletier, 1841)

Osmia anthocopoides Schenck, 1853. Jahrb. Ver. Naturk. Nassau, 9: 181

Osmia caementaria Gerstaecker, 1869. Stettin. ent. Ztg., 30: 339

Osmia clavipennis Schenck, 1870. Stettin. ent. Ztg., 31: 106

Osmia hybrida Pérez, 1879. Act. Soc. Linn. Bordeaux, 33: 200

Osmia romana Morice, 1901. Trans. ent. Soc. London: 169, 176

Fertonella algerica Benoist, 1969. Bull. Soc. entomol. France, 74: 244

Especie paleártica y establecida en Nueva York, según Michener (2000). En Canarias existe una población, Hoplitis anthocopoides perambigua (Peters, 1975), diferenciada de la subespecie nominal, que es la que aparece en la Península Ibérica.

Hoplitis (Hoplitis) benoisti (Alfken, 1935)

Osmia benoisti Alfken, 1935. Veröff. dt. Kolon. u. ÜberseeMus. Bremen, 1: 189

Distribución mediterránea occidental.

Hoplitis (Hoplitis) benoisti benoisti (Alfken, 1935)

Osmia morawitzi Pérez, 1879. Act. Soc. Linn. Bordeaux, 33: 199 (non Gerstaecker, 1869; nec Ducke, 19004)

$4 \quad$ El volumen 25 [1899-1900] de Berichte des NaturwissenschaftlichMedizinischen Vereins in Innsbruck fue publicado en 1900, aunque el trabajo de Ducke tiene fecha de 1899.
Osmia benoisti Alfken, 1935. Veröff. dt. Kolon. u. ÜberseeMus. Bremen, 1: 189 (nomen novum para Osmia morawitzi Pérez, 1879)

Osmia grinincensis Benoist, 1969. Bull. Soc. entomol. France, 74: 244

Subespecie distribuida por la zona noroccidental del Mediterráneo (Península Ibérica, sur de Francia, Córcega, Cerdeña e Italia).

Hoplitis (Hoplitis) benoisti gregaria (Warncke, 1992)

Osmia benoisti gregaria Warncke, 1992. Linzer biol. Beitr., 24 (1): 116

Subespecie distribuida por Marruecos, Argelia y Túnez.

Hoplitis (Hoplitis) bihamata (Costa, 1885)

Osmia bihamata Costa, 1885. Atti. Accad. Sc. fis. mat. Napoli, 2: 20

Osmia corsica Ferton, 1901. Bull. Soc. entomol. France, 4: 61

Especie distribuida por Marruecos, en el norte de África, y Córcega y Cerdeña, en el Mediterráneo.

Hoplitis (Hoplitis) brevispora (Warncke, 1992)

Osmia brevispora Warncke, 1992. Linzer biol. Beitr., 24 (1): 110

Especie endémica de Marruecos.

Hoplitis (Hoplitis) brunnescens (Benoist, 1950)

Osmia brunnescens Benoist, 1950. Bull. Soc. Scienc.Nat. Maroc, 30: 187

Especie endémica de Marruecos.

Hoplitis (Hoplitis) conosimilis van der Zanden, 1992

Hoplitis (Hoplitis) conosimilis van der Zanden, 1992. Reichenbachia, 29 (12): 67

Especie distribuida en Marruecos y Túnez.

Hoplitis (Hoplitis) crenulata (Morawitz, 1871)

Osmia crenulata Morawitz, 1871. Horae Soc. entomol. Ross., 8: 208

Especie distribuida por el sur de Europa (Francia, Península Ibérica y Chipre), el norte de África (Argelia y Marruecos), Palestina y Transcaucasia.

Hoplitis (Hoplitis) ctenophora (Benoist, 1934)

Osmia ctenophora Benoist, 1934. Bull. Soc. entomol. France, 39: 159

Especie distribuida en Marruecos y Argelia.

Hoplitis (Hoplitis) fertoni (Pérez, 1890)

Osmia fertoni Pérez, 1890. En: Ferton, Act. Soc. Linn. Bordeaux, 44: 206

Osmia albispina Pérez, 1895. Esp. Nouv. Mellif. Barbarie: 16

Osmia mecheriana Pérez, 1902. Act. Soc. Linn. Bordeaux, 57: 68

Especie distribuida en el norte de África, Marruecos, Argelia y Túnez, y en España. 
Van der Zanden (1988a, 1992a) no consideraba sinónima a Hoplitis mecheriana, sino como una especie de Túnez, diferenciada de Hoplitis fertoni.

\section{Hoplitis (Hoplitis) fortispina (Pérez, 1895)}

Osmia fortispina Pérez, 1895. Esp. nouv. Mellif. Barbarie: 15 Osmia fortispina Pérez, 1902. Proc. ver. Soc. Linn. Bordeaux, 57: 66

Descrita de "Barbarie", es una especie endémica de Argelia.

Hoplitis (Hoplitis) hoggara (Warncke, 1992)

Osmia hoggara Warncke, 1992. Linzer biol. Beitr., 24 (1): 109

Especie distribuida en Marruecos y Argelia.

Hoplitis (Hoplitis) insularis (Schmiedeknecht, 1885)

Osmia insularus Schmiedeknecht, 1885. Apidae Europaeae, 2 (11): 908

Osmia vaulogeri Pérez, 1895. Esp. nouv. Mellif. Barbarie: 16

Especie mediterránea occidental, conocida de España, Cerdeña, Sicilia e Italia peninsular en Europa, y Marruecos, Argelia y Túnez en el norte de África.

Hoplitis (Hoplitis) jheringii (Ducke, 1898)

Osmia jheringii Ducke, 1898. Ent. Nachr., 24: 260

Especie mediterránea, incluidas Italia y la Península Balcánica en Europa, y Marruecos, Túnez y Egipto en el norte de África.

Hoplitis (Hoplitis) jheringii hirundo (Warncke, 1992)

Osmia jheringii hirundo Warncke, 1992. Linzer biol. Beitr., 24 (1): 107

Subespecie endémica de Marruecos.

Hoplitis (Hoplitis) jheringii jheringii (Ducke, 1898)

Osmia jheringii Ducke, 1898. Ent. Nachr., 24: 260

Subespecie distribuida en ltalia, Península Balcánica y Egipto.

Hoplitis (Hoplitis) jheringii urbica (Warncke, 1992)

Osmia jheringii urbica Warncke, 1992. Linzer biol. Beitr., 24 (1): 108

Subespecie endémica de Túnez.

Hoplitis (Hoplitis) latuspinosa van der Zanden, 1992

Hoplitis (Hoplitis) latuspinosa van der Zanden, 1992. Linzer Biol. Beitr. 24 (1): 69

Especie endémica de Marruecos.

Hoplitis (Hoplitis) lefeberi van der Zanden, 1991

Hoplitis (Hoplitis) lefeberi van der Zanden, 1991. Reichenbachia, 28 (31): 169

Especie endémica de Marruecos.

\section{Hoplitis (Hoplitis) lepeletieri (Pérez, 1879)}

Osmia lepeletieri Pérez, 1879. Act. Soc. Linn. Bordeaux, 33: 198

Especie europea con tendencia orófila, repartida por los Pirineos, franceses y españoles, los Alpes austríacos e italianos, otras regiones de Italia, y Alemania.

Hoplitis (Hoplitis) loreicornis (Benoist, 1934)

Osmia loreicornis Benoist, 1934. Bull. Soc. entomol. France, 39: 159

Especie endémica de Marruecos.

Hoplitis (Hoplitis) loti (Morawitz, 1868)

Osmia loti Morawitz, 1868. Horae Soc. entomol. Ross., 5 [1867-1868]: 66

Osmia morawitzi Gerstaecker, 1869. Stettin. ent. Ztg., 30: 344 (non Pérez, 1879)

Osmia difformis Pérez, 1879. Act. Soc. Linn. Bordeaux, 33: 202

Especie distribuida por Europa central, en Alemania y Austria, los Alpes franceses, italianos y suizos, y Europa meridional, incluidos los Pirineos franceses, España, Sicilia, Croacia, Eslovenia y Bosnia.

Hoplitis (Hoplitis) lysholmi (Friese, 1899)

Osmia lysholmi Friese, 1899. Ent. Nachr., 25: 331

Especie citada de Europa meridional (España, y Rodas en Grecia), Turquía y Oriente Próximo (Líbano e Israel).

Hoplitis (Hoplitis) manicata (Morice, 1901)

Osmia manicata Morice, 1901. Trans. ent. Soc. London: 166, 176

Especie distribuida por zonas cálidas de Europa central y desde Austria y Rumanía hasta los Balcanes; en Europa meridional, por Francia (incluida Córcega) y Grecia (incluida Creta); en Turquía y en el norte de África (Argelia).

Hoplitis (Hoplitis) mucida (Dours, 1873)

Osmia mucida Dours, 1873. Revue Mag. Zool., 1 (3): 293.

Osmia taorminaensis Strand, 1919. Archiv. f. Naturg., 83A (11): 63

Osmia maroccana Benoist, 1929. Ann. Soc. entomol. France, 98: 250 (non Benoist, 1928)

Distribución mediterránea, incluidos el sur de Francia, España, Italia y una cita de Suiza y, en el norte de África, Marruecos, Argelia y Túnez, además de Israel, en Oriente Próximo.

Hoplitis (Hoplitis) mucidoides van der Zanden, 1990

Hoplitis mucidoides van der Zanden, 1990. Reichenbachia, 28 (9): 51

Hoplitis mucida, auctt. (non Dours, 1873)

Osmia chobauti Pérez, 1902. Proc. ver. Soc. Linn. Bordeaux, 57: 66

Osmia mucida var. stecki Frey-Gessner, 1908. Mitt. schweiz. ent. Ges., 11: 280 
Especie distribuida por Francia y España, en Europa meridional, Suiza, en Europa central, en Argelia y en la provincia española de Melilla, en el norte de África, y además en Palestina, en Oriente Próximo.

En relación con opiniones distintas sobre Hoplitis mucidoides van der Zanden, 1990 y Osmia mucida Dours, 1873 véanse van der Zanden (1990) y Rasmont et al. (1995), así como Warncke (1992a) y Schwarz et al. (1996), que difieren de los anteriores.

\section{Hoplitis (Hoplitis) ochraceicornis (Ferton, 1902)}

Osmia ochraceicornis Ferton, 1902. Ann. Soc. entomol. France, 71: 499

Fertonella seyrigi Benoist, 1969. Bull. Soc. entomol. France, 74: 245

Especie con tendencia orófila, que se conoce de los Alpes y los Pirineos, además de otras zonas de Europa meridional, tales como el sur de Francia, España, Italia y Macedonia.

Hoplitis (Hoplitis) oreades (Benoist, 1934)

Osmia oreades Benoist, 1934. Bull. Soc. entomol. France, 39: 107 Osmia pectinifera Benoist, 1934. Bull. Soc. entomol. France, 39: 159

Especie endémica de Marruecos, citada del Gran Atlas.

Van der Zanden (1988a) consideraba a Hoplitis pectinifera (Benoist, 1934), que también él citaba de Marruecos (van der Zanden 1985, 1988a), como una especie válida.

Hoplitis (Hoplitis) pallicornis (Friese, 1895)

Osmia pallicornis Friese, 1895. Ent. Nachr., 21: 131

Especie distribuida desde Italia, por la zona septentrional del Mediterráneo, Grecia, Croacia y Península Balcánica, hasta Jordania, y también existe una antigua cita de España (Alfken, 1927; Ceballos, 1956). Por otro lado, Ducke (1900) incluía Osmia pallicornis como sinónima de Osmia difformis Pérez, 1879, especie ésta que, de acuerdo con Schwarz et al. (1996), es sinónima de Hoplitis loti.

\section{Hoplitis (Hoplitis) ravouxi (Pérez, 1902)}

Osmia ravouxi Pérez, 1902. Proc. ver. Soc. Linn. Bordeaux, 57: 67 Osmia rhinotropis Pérez, 1902. Proc. ver. Soc. Linn. Bordeaux, 57: 68

Hoplitis brachyceros Blüthgen, 1920. Stettin. ent. Ztg., 81: 31 Hoplitis ebmeri van der Zanden, 1989. Entomol. Abh. Mus. Tierkd. Dresden, 53 (6): 83

Especie distribuida por Europa meridional, desde ciertas montañas ibéricas hasta Europa central en el norte y Rumanía por el este.

La cita "Cataluña" referenciada por varios autores (Benoist, 1928a; Ceballos, 1956, entre otros) podría tratarse de un error de interpretación de Benoist al confundir «Barcelonette» de los Alpes, que aparece en el material de Pérez que él estudia, con Barcelona -España-, ya que las otras citas ibéricas de esta especie son de zonas orófilas (Sierra Nevada, $2.800 \mathrm{~m}$ o Sierra de la Estrela), extremo éste, no obstante, que posiblemente no se podrá confirmar, tal como se señaló al principio del texto.

Por otro lado, van der Zanden (1988a) y Rasmont et al. (1995) consideran a Hoplitis ebmeri como una especie válida.

Hoplitis (Hoplitis) sexcinctella (Pérez, 1895)

Osmia sexcinctella Pérez, 1895. Esp. nouv. Mellif. Barbarie: 14

Descrita de "Barbarie", se distribuye por Argelia y Marruecos.

Hoplitis (Hoplitis) submanicata van der Zanden, 1984 Hoplitis (Hoplitis) submanicata van der Zanden, 1984. Reichenbachia, 22 (23): 180

Especie distribuida por Sicilia, en Italia, y Marruecos.

Hoplitis (Hoplitis) taenioceras (Benoist, 1927)

Osmia taenioceras Benoist, 1927. Bull. Soc. sci. nat. Maroc, 7 : 173

Especie distribuida por Marruecos y Argelia.

Hoplitis (Hoplitis) tenuiserrata (Benoist, 1950)

Osmia tenuiserrata Benoist, 1950. Bull. Soc. Scienc.Nat. Maroc, 30: 45

Osmia gibbifera Benoist, 1950. Bull. Soc. Scienc.Nat. Maroc, 30: 50

Especie endémica de Marruecos.

Hoplitis (Hoplitis) teucrii (Benoist, 1927)

Osmia teucrii Benoist, 1927. Bull. Soc. sci. nat. Maroc, 7: 171

Especie endémica de Marruecos.

Subgénero Megahoplitis Tkalcu, 1993

Hoplitis (Megahoplitis) Tkalcu, 1993. Bull. Soc. Entomol. Mulhouse: 55

ESPECIE TIPO: Osmia tigrina Morawitz, $1871=$ Hoplitis tigrina (Morawitz, 1871), por monotipia.

Distribución mediterránea, por Grecia, Turquía y el norte de África; Michener (2000) le asignaba una única especie.

Hoplitis (Megahoplitis) tigrina (Morawitz, 1871)

Osmia tigrina Morawitz, 1871. Horae Soc. entomol. Ross., 8: 206 Osmia deserti Benoist, 1934. Bull. Soc. entomol. France, 39: 106

Especie distribuida por Grecia, Turquía y el norte de África. 
Subgénero Nasutosmia Griswold \& Michener, 1998

Hoplitis (Nasutosmia) Griswold \& Michener, 1998. J. Kansas Entomol, Soc., 70 [1997]: 225

ESPECIE TIPO: Osmia nasuta Friese, 1899, por designación original

Distribución mediterránea occidental, por el norte de África y España; Michener (2000) le asignaba, con dudas, dos especies.

Hoplitis (Nasutosmia) corniculata van der Zanden, 1989 Hoplitis (Micreriades) corniculata van der Zanden, 1989. Entomol. Abh. Mus. Tierkd. Dresden, 53 (6): 81

Especie distribuida por Marruecos y Argelia, en el norte de África, y España, en el sur de Europa.

Hoplitis (Nasutosmia) nasuta (Friese, 1899)

Osmia nasuta Friese, 1899. Ent. Nachr., 25: 27

Osmia rhynchaena Pérez, 1905. Butll. Inst. Catalana Hist. Nat., 6: 83

Especie distribuida por Marruecos y Argelia en el norte de África y España en el sur de Europa.

Subgénero Pentadentosmia Warncke, 1991

Osmia (Pentadentosmia) Warncke, 1991. Entomofauna, 12: 14 ESPECIE TIPO: Osmia quinquespinosa Friese, 1899, por designación original

Distribuido por la paleártica occidental, comprende especies desérticas en su mayoría, que aparecen desde Canarias, a través del área mediterránea, sur de Sudán y por el este en Asia Central y Beluchistán. Michener (2000) le adjudicaba 24 especies y, de ellas, 17 paleárticas.

Hoplitis (Pentadentosmia) cadiza (Warncke, 1991) Osmia cadiza Warncke, 1991. Entomofauna, 12: 20

Especie conocida de España, Marruecos y Túnez.

Hoplitis (Pentadentosmia) goulemina (Warncke, 1991) Osmia goulemina Warncke, 1991. Entomofauna, 12: 18

Especie endémica de Marruecos.

Hoplitis (Pentadentosmia) helouanensis (Friese, 1899) Osmia helouanensis Friese, 1899. Ent. Nachr., 25: 61

Especie distribuida por el norte de África (Marruecos, Túnez, Egipto) y en Israel.

Hoplitis (Pentadentosmia) laevifrons (Morawitz, 1872) Osmia laevifrons Morawitz, 1872. Verh. zool.-bot. Ges. Wien., 22: 360 (non Pérez, 1879)

Especie distribuida por Europa central y meridional, Marruecos y Argelia, en el norte de África, en el área mediterránea oriental desde Italia hasta Turquía y, en Asia, por el territorio transcaucásico.
Hoplitis (Pentadentosmia) meyeri (Benoist, 1934)

Osmia meyeri Benoist, 1934. Bull. Soc. entomol. France, 39: 108

Especie distribuida por Marruecos y Argelia.

Hoplitis (Pentadentosmia) pustinia (Warncke, 1991)

Osmia moricei Friese, 1899. Ent. Nachr., 25: 26 (non Friese, 1897) Osmia pustinia Warncke, 1991. Entomofauna, 12: 16

Especie distribuida por Canarias en España, Argelia, Marruecos y Túnez en el norte de África, y Jordania e Israel en Oriente Medio.

Hoplitis (Pentadentosmia) quinquespinosa (Friese, 1899)

Osmia quinquespinosa Friese, 1899. Ent. Nachr., 25: 26

Osmia consanguinea Benoist, 1929. Bull. Soc. entomol. France: 98

Osmia neptunea Benoist, 1929. Bull. Soc. entomol. France: 99

Especie conocida de España, el norte de África (Argelia, Marruecos,Túnez) y de Israel.

Por otro lado, para van der Zanden (1983), Osmia consanguinea es una buena especie -del género Anthocopa- de España y del norte de África; luego, en 1988, ya no recogía su anterior cita de España (van der Zanden, 1988a) y en 1992 (van der Zanden, 1992a) establece Osmia neptunea como sinónima de ella.

Subgénero Platosmia Warncke, 1990

Osmia (Platosmia) Warncke, 1990. Entomofauna, 11: 482 ESPECIE TIPO: Osmia platalea Warncke, 1990, por designación original

Distribución en la región paleártica, desde Marruecos a través del norte de África hasta Turquía y Mongolia. Michener (2000) le adjudicaba 8 especies.

Hoplitis (Platosmia) adustus van der Zanden, 1991

Hoplitis (Platosmia) adustus van der Zanden, 1991. Linzer. biol. Beitr., 23 (1): 347

Especie endémica de Marruecos.

Hoplitis (Platosmia) africana (Warncke, 1990)

Osmia africana Warncke, 1990. Entomofauna, 11: 486

Especie distribuida por Marruecos, Argelia e Israel.

Hoplitis (Platosmia) aristotelis (Warncke, 1990)

Osmia aristotelis Warncke, 1990. Entomofauna, 11: 485

Especie endémica de Marruecos.

Hoplitis (Platosmia) dumonti (Warncke, 1990)

Osmia dumonti Warncke, 1990. Entomofauna, 11: 489

Especie distribuida por Marruecos, Argelia y Túnez.

\footnotetext{
Van der Zanden (1988a) daba la referencia de una "Hoplitis (Tridentosmia) dumonti (Benoist, 1929)" de Túnez.
} 
Hoplitis (Platosmia) incognita Van der Zanden, 1996 Hoplitis (Platosmia) incognita Van der Zanden, 1996. Linzer. biol. Beitr., 28 (2): 887

Especie endémica de Marruecos.

Hoplitis (Platosmia) lucidula (Benoist, 1934)

Osmia lucidula Benoist, 1934. Bull. Soc. entomol. France, 39: 107

Especie endémica de Marruecos.

Hoplitis (Platosmia) platalea (Warncke, 1990)

Osmia platalea Warncke, 1990. Entomofauna, 11: 484

Especie endémica de Marruecos.

Subgénero Prionohoplitis Tkalcu, 1993

Hoplitis (Prionohoplitis) Tkalcu, 1993. Bull. Soc. Entomol. Mulhouse: 55

EsPECIE TIPO: Osmia curvipes Morawitz, 1871, por designación original

Distribución en la región paleártica, por el área mediterránea, desde España y Argelia hasta Irán y Kazajistán, por el este. Michener (2000) le adjudicaba 6 especies.

Hoplitis (Prionohoplitis) brachypogon (Pérez, 1879)

Osmia brachypogon Pérez, 1879. Act. Soc. Linn. Bordeaux, 33: 195

Osmia carsophila Ducke, 1900. Ber. naturw-med. Ver. Innsbruck, 25: 116

Osmia seyrigi Benoist, 1934. Bull. Soc. entomol. France, 39: 106

Especie distribuida a través del área mediterránea septentrional, desde España hasta Turquía e Israel.

Para van der Zanden (1985, 1988b), Osmia seyrigi es una especie válida perteneciente a Hoplitis (Tridentosmia). Rasmont et al. (1995) consideraban esta especie en el subgénero Alcidamea, pero Michener (2000) -basándose en Griswold \& Michener (1998)- la incluía aquí, y también a Hoplitis insolita (Benoist, 1928).

Por otro lado, para Warncke (1991e), Osmia carsophila constituía una especie válida.

Hoplitis (Prionohoplitis) campanularis (Morawitz, 1877) Osmia campanularis Morawitz, $1877^{6}$. Horae Soc. entomol. Ross., 14: 42

Osmia digitata Friese, 1899. Ent. Nachr., 25: 61

Especie con distribución íbero-magrebí, por Argelia, Marruecos y España.

Warncke (1991g, p. 736) consideraba un nuevo estatus para Osmia sexcinctella Pérez, 1895, Osmia campanularis sexcinctella Pérez, 1895, y establecía como sinónima de ella a Osmia digitata, pero sin estudiar, al

\footnotetext{
$6 \quad$ Véase la nota al pie en Osmia dentiventris, en relación con el año de publicación de estas especies.
}

no encontrarlo, ese material de Pérez. Mavromoustakis (1947) separaba para España la subespecie Osmia digitata ibericola Mavromoustakis, 1947. Van der Zanden (1988a) también consideraba sinónima a Osmia digitata, pero de Hoplitis (Alcidamea) campanularis, aunque en Rasmont et al. (1995), fue Osmia campanularis la que pasó a sinonimia de Hoplitis digitata - que es como aparecía en van der Zanden (1984). Ebmer (2003) reconocía de nuevo las dos subespecies anteriores.

Por otro lado, la inclusión en el texto de esta especie y de Hoplitis epeoliformis (Ducke, 1899) en el subgénero Prionohoplitis, en lugar de en Alcidamea, se hace de acuerdo con Griswold \& Michener (1998).

\section{Hoplitis (Prionohoplitis) campanularis sexcinctella} (Pérez, 1895)

Osmia sexcinctella Pérez, 1895. Esp. nouv. Mellif. Barbarie: 14

Descrita de "Barbarie", esta subespecie se distribuye por Argelia y Marruecos.

Hoplitis (Prionohoplitis) campanularis ibericola (Mavromoustakis, 1947)

Osmia digitata ibericola Mavromoustakis, 1947. Eos, 23: 357

Subespecie endémica de España.

Hoplitis (Prionohoplitis) curvipes (Morawitz, 1871)

Osmia curvipes Morawitz, 1871. Horae Soc. entomol. Ross., 8: 204

Especie distribuida por el área mediterránea, por Francia, Italia y Grecia en Europa, Argelia en el norte de África, hasta Siria.

Hoplitis (Prionohoplitis) epeoliformis (Ducke, 1899)

Osmia epeoliformis Ducke, 1899. Ent. Nachr., 25: 212

Especie distribuida por Argelia, Marruecos y Jordania.

Para Tkalcu (1975b), Osmia epeoliformis pertenece a Anthocopa (Anthocopa) y para Rasmont et al. (1995), al subgénero Anthocopa (Alcidamea).

\section{Hoplitis (Prionohoplitis) insolita (Benoist, 1928)}

Osmia insolita Benoist, 1928. Ann. Soc. entomol. France, 97: 18

Especie endémica de Argelia.

Para van der Zanden (1985, 1988a) pertenece a Hoplitis (Tridentosmia). Ésta y las otras del subgénero, como se ha comentado antes, se mantienen aquí de acuerdo, además, con Michener (2000).

Hoplitis (Prionohoplitis) lecerfi (Benoist, 1928)

Osmia lecerfi Benoist, 1928. Bull. Soc. Scienc. Nat. Maroc, 8: 213

Especie endémica de Marruecos.

Warncke (1991e) se cuestionaba si Hoplitis lecerfi es sólo una subespecie de Hoplitis brachypogon. 
Género Hoplosmia Thomson, 1872

Osmia (Hoplosmia) Thomson, 1872. Hym. Scand., 2: 233, sin especies; Schmiedeknecht, 1885. Apidae Europaeae., 2(11): 889 ESPECIE TIPO: Apis spinulosa Kirby, 1802, por designación de Michener, 1941

Distribución en Europa, desde el norte hasta el Mediterráneo, el norte de África, e Israel en Oriente Próximo; Michener (2000) le asignaba 13 especies.

\section{Subgénero Hoplosmia Thomson, 1872}

Subgénero repartido desde el norte de Europa hasta el Mediterráneo, y Egipto; Michener (2000) le asignaba tres especies.

Hoplosmia (Hoplosmia) picena Tkalcu, 1999

Hoplosmia (Hoplosmia) picena Tkalcu, 1999. Bull. Soc. Entomol. Mulhouse: 11

Especie endémica de Italia.

Hoplosmia (Hoplosmia) spinulosa (Kirby, 1802)

Osmia spinulosa Kirby, 1802. Monogr. Apum Angliae, 2: 261 Osmia euchreiformis Radoszkoswki, 1882. Wiadom z nauk. przyrodz. Warszawa, 2: 78

Distribución europea, excepto el norte, y con tendencia xerotérmica; se reparte en dos subespecies. Una antigua cita de España, referenciada por Ceballos (1956), debería ser constatada en el futuro.

Dubitzky et al. (2005) la listan como una especie de Osmia.

Subgénero Odontanthocopa Tkalcu, 1974

Anthocopa (Odontanthocopa) Tkalcu, 1974. Acta ent. Bohemoslov., 71: 125

ESPECIE TIPO: Osmia bidentata Morawitz, 1876, por designación original

Anthocopa (Odonterythrosmia) Tkalcu, 1974. Acta ent. Bohemoslov., 71: 131

ESPECIE TIPO: Osmia fallax Pérez, 1895, por designación original

Distribución por el área mediterránea hasta Europa suroriental; Michener (2000) le asignaba 9 especies.

Hoplosmia (Odontanthocopa) anceyi (Pérez, 1879) Osmia anceyi Pérez, 1879. Act. Soc. Linn. Bordeaux, 33: 187

Especie distribuida por Suiza, Austria y Alemania, en Europa central y por Francia, la Península Ibérica e Italia y Marruecos, en el área mediterránea occidental.

Hoplosmia (Odontanthocopa) anceyi anceyi (Pérez, 1879) Osmia anceyi Pérez, 1879. Act. Soc. Linn. Bordeaux, 33: 187

Subespecie repartida por Suiza, Austria y Alemania, en Europa central y por Francia, la Península Ibérica e Italia, en el sur de Europa.
Hoplosmia (Odontanthocopa) anceyi biarmica (van der Zanden, 1994)

Hoplosmia (Odontanthocopa) anceyi biarmica van der Zanden, 1994. Linzer. Biol. Beitr., 26 (2): 1114

Subespecie endémica de Marruecos.

Hoplosmia (Odontanthocopa) bidentata (Morawitz, 1876) Osmia bidentata Morawitz, 1876. Horae Soc. entomol. Ross., $12: 38,39$

Osmia affinis Frivaldsky, 1876. Termesz. Közlem., 13: 360

Especie distribuida por Europa central y meridional, incluida España, área mediterránea, incluidas Croacia y Turquía, Palestina en Oriente Próximo, Cáucaso y todo el norte de África.

Hoplosmia (Odontanthocopa) dido (Gribodo, 1894)

Osmia dido Gribodo, 1894. Boll. Soc. entomol. Ital., 26: 289

Osmia abbreviata Pérez, 1895. Esp. nouv. Mellif. Barbarie: 13

Osmia compacta Pérez, 1896. Corr. Esp. nouv. Mellif. Barbarie: no paginada

Especie distribuida por Argelia y Túnez; las dos formas sinonímicas de Pérez fueron descritas de "Barbarie"

Tkalcu (1975b) consideraba a Osmia compacta como una especie independiente.

Hoplosmia (Odontanthocopa) fallax (Pérez, 1895)

Osmia fallax Pérez, 1895. Esp. nouv. Mellif. Barbarie: 13

Descrita de "Barbarie", Benoist (1924) corregía su distribución sobre el material de Pérez, como "únicamente de España"; no obstante, van der Zanden (1988a), le asignaba una distribución por España y el norte de África.

Se incluye aquí Hoplosmia fallax, de acuerdo con Michener (2000) que hacía la sinonimia del subgénero Odonterythrosmia Tkalcu, 1974, que van der Zanden (1988a) y Rasmont et al. (1995) situaban como independiente de Odontanthocopa.

Hoplosmia (Odontanthocopa) ligurica (Morawitz, 1868) Osmia ligurica Morawitz, 1868. Horae Soc. entomol. Ross., 5 [1867-1868]: 150

Osmia detrita Pérez, 1879. Act. Soc. Linn. Bordeaux, 33: 188

Especie distribuida por Europa central y el área mediterránea, desde España hasta Israel. Ebmer (2005) referenciaba también su existencia en Portugal.

Hoplosmia (Odontanthocopa) scutellaris (Moratwitz, 1868)

Osmia scutellaris Morawitz, 1868. Horae Soc. entomol. Ross., 5 (1867-1868): 151

Anthocopa olgae Tkalcu, 1978. Cas. slezsk. Mus. Opava, 27: 159

Distribuida por el área mediterránea, desde España y el norte de África (Argelia) hasta Grecia, Chipre, Asia Menor y Palestina, llegando en Europa central hasta Hungría. 
Subgénero Paranthocopa Tkalcu, 1974

Anthocopa (Paranthocopa) Tkalcu, 1974. Acta ent. Bohemoslov., 71: 132

ESPECIE TIPO: Osmia pinguis Pérez, 1895, por designación original

Distribución por el norte de África e Israel; incluye una sola especie (Michener, 2000).

Hoplosmia (Paranthocopa) pinguis (Pérez, 1895)

Osmia pinguis Pérez, 1895. Esp. nouv. Mellif. Barbarie: 12 Osmia indivisa Benoist, 1928. Bull. Soc. Scienc. Nat. Maroc, 8: 214

Descrita de "Barbarie", se reparte por el sur del área mediterránea (Marruecos, Argelia, Túnez, Palestina) y España.

\section{Género Osmia Panzer, 1806}

Osmia Panzer, 1806. Krit. Revis. Insektenf. Deutsch., 2: 230 ESPECIE TIPO: Apis bicornis Linnaeus, $1758=$ Apis rufa Linnaeus, 1758 = Anthophora bicornis (Fabricius, 1804), por designación de Latreille, 1810

Amblys Klug, 1807. Mag. Insektenk., 6: 198, 226

ESPECIE TIPO: Apis bicornis Linnaeus, $1758=$ Osmia bicornis (Linnaeus, 1758) = Apis rufa Linnaeus, $1758=$ Osmia rufa (Linnaeus, 1758), por designación de Latreille, 1811

Osmia (Ceratosmia) Thomson, 1872. Hym. Scand., 2: 232

ESPECIE TIPO: Apis bicornis Linnaeus, $1758=$ Osmia rufa (Linnaeus, 1758), por designación de Sandhouse, 1939

Osmia (Aceratosmia) Schmiedeknecht, 1885. Apidae Europaeae, 2 (11): 885

ESPECIE TIPO: Osmia emarginata Lepeletier, 1841, por designación de Sandhouse, 1939

Osmia (Pachyosmia) Ducke, 1900. Ber. naturw-med. Ver. Innsbruck, 25: 18

ESPECIE TIPO: = Apis rufa Linnaeus, 1758 = Osmia rufa (Linnaeus, 1758), por designación de Sandhouse, 1939

Existen distintas opiniones (Tkalcu, 1969; van der Zanden 1988a; Rasmont et al., 1995 ó Michener, 2000, por ejemplo) sobre la separación de Osmia emarginata, Osmia mustelina Gerstaecker, 1869, Osmia nasoproducta Ferton, 1910 y Osmia proboscidea Benoist, 1950 en el subgénero Aceratosmia, fundamentalmente por la presencia en sus individuos de sólo 4 segmentos en los palpos labiales (Tkalcu, 1969); están incluidas aquí en el subgénero nominal.

\section{Subgénero Allosmia Tkalcu, 1974}

Osmia (Allosmia) Tkalcu, 1974. Beitr. Ent., Berlin, 24 (5/8): 331 ESPECIE TIPO: Osmia rufohirta, Latreille, 1811, por designación original

Michener (2000) incluía Allosmia (al igual que Erythrosmia Schmiedeknecht, 1885) como subgéneros del género Osmia, al considerar que ambos subgéneros no presentan los rasgos del género Hoplitis, si bien lo hacía con ciertas reservas. De igual modo, discrepaba de otros especialistas (Tkalcu, 1974b o van der Zanden, 1988a) y situaba la mayoría de las especies del subgénero Allosmia en Osmia (Erythrosmia).

Distribución por Europa central y meridional y el norte de África.

\section{Osmia (Allosmia) cognata Pérez, $1895^{7}$}

Osmia cognata Pérez, 1895. Esp. nouv. Mellif. Barbarie: 17

Especie citada originalmente de "Barbarie" y cuya validez y denominación deben ser comprobadas.

Osmia (Allosmia) Ihotelleriei Pérez 1887

Osmia lhotelleriei Pérez 1887. Rev. Ent., 6 : 178

Especie distribuida por el norte de África: Marruecos, Argelia, Libia y Egipto.

Osmia (Allosmia) melanura Morawitz, 1871

Osmia melanura Morawitz, 1871. Horae Soc. entomol. Ross., 8: 203

Especie mediterránea occidental, repartida por Francia, Italia, incluida Sicilia, y Grecia.

Osmia (Allosmia) rufohirta Latreille, 1811

Osmia rufohirta Latreille, 1811. Encycl. méthod. Ins., 8: 580

Osmia fulvohirta Lepeletier, 1841. His. Nat. Ins. Hym., 2: 322

Osmia spiniventris Giraud, 1857. Verh. zool.-bot. Ges. Wien., 7: 181

Especie paleártica occidental, distribuida a través de Europa central y meridional, incluidas España, Francia, Italia, Croacia, Grecia y Albania, y en Marruecos, Asia Menor, el Cáucaso y el Turkestán.

Van der Zanden (1988a) reconocía como una subespecie distinta de Marruecos a Osmia rufohirta var. soror Benoist, 1950.

Osmia (Allosmia) rutila Erichson, 1835

Osmia rutila Erichson, 1835. En: Waltl, Reise d'Tyrol, 2: 107

?Osmia baetica Spinola, 1843. Ann. Soc. entomol. France ( $2^{\mathrm{a}}$ sér.), 1: 142

Osmia xanthognatha Pérez, 1895. Esp. nouv. Mellif. Barbarie: 12

Distribución íbero-magrebí, en España y Marruecos.

Osmia (Allosmia) sybarita Smith, 1853

Osmia sybarita Smith, 1853. Cat. Brit. Hym. Brit. Mus., 1: 140

Especie distribuida en su forma nominal fuera del territorio considerado, por la Península Balcánica, Albania, Chipre e islas griegas, y por el norte de África.

Osmia (Allosmia) sybarita fossoria Pérez, 1890

Osmia fossoria Pérez, 1890. En: Ferton, Act. Soc. Linn. Bordeaux, 44: 201

Existe una especie americana, Osmia cognata Cresson, 1864, sinónima de la también americana Osmia simillima Smith, 1853. 
Osmia duckei Friese, 1899. Ent. Nachr., 25: 27

Esta subespecie se conoce de Argelia y Túnez.

Subgénero Erythrosmia Schmiedeknecht, $1885^{8}$

Osmia (Erythrosmia) Schmiedeknecht, 1885. Apidae Europaeae., 2 (11): 886

ESPECIE TIPO: Osmia andrenoides Spinola, 1808, por designación de Cockerell, 1922

Distribución mediterránea y asiática central; Michener (2000) le asignaba 13 especies.

Osmia (Erythrosmia) andrenoides Spinola, 1808

Osmia andrenoides Spinola, 1808. Insect. Ligur., 2: 61

Especie distribuida por Europa central y meridional, incluida el área mediterránea, desde España hasta Grecia y los Balcanes, así como por Transcaucasia.

Osmia (Erythrosmia) erythrogastra Ferton, 1905

Osmia erythrogastra Ferton, 1905. Ann. Soc. entomol. France, 74: 56

Especie mediterránea septentrional, distribuida desde Córcega, hasta Turquía y Chipre.

Osmia (Erythrosmia) sparsipuncta Alfken, 1914

Osmia sparsipuncta Alfken, 1914. Mem. Soc. ent. Belg., 22: 200

Especie endémica de Argelia.

Subgénero Helicosmia Thomson, 1872

Osmia (Helicosmia) Thomson, 1872. Hym. Scand., 2: 233, sin especies; Schmiedeknecht, 1885. Apidae Europaeae, 2 (11): 888 ESPECIE TIPO: Apis aurulenta Panzer, 1799, por designación de Michener, 1941

Osmia (Chalcosmia) Schmiedeknecht, 1885. Apidae Europaeae, 2 (11): 886

ESPECIE TIPO: Apis fulviventris Panzer, 1798 (non Scopoli, 1763) = Apis niveata Fabricius, 1804, por designación de Sandhouse, 1939

Gnathosmia Robertson, 1903. Trans. Am. Entomol. Soc., 29 165,171

ESPECIE TIPO: Osmia georgica Cresson, 1878, por monotipia y designación original

Osmia (Cryptosmia) Yasumatsu \& Hirashima, 1950. Mushi, 21: 14 ESPECIE TIPO: Osmia satoi Yasumatsu \& Hirashima, 1950, por designación original

Aunque Helicosmia presenta distribución paleártica, Osmia caerulescens (Linnaeus, 1758) es holártica; Michener (2000) le asignaba 53 especies paleárticas.

Para van der Zanden (1988a, 1998), Rasmont et al. (1995) y Tkalcu (2000), Chalcosmia es un subgénero distinto de Helicosmia.

Véase el comentario incluido en el subgénero Allosmia Tkalcu, 1974.
Osmia (Helicosmia) alfkenii Ducke, 1900

Osmia alfkenii Ducke, 1900. Ber. naturw-med. Ver. Innsbruck, 25: 263

Osmia crinita Alfken 1942. Veröff. dt. Kolon. u.Übersee-Mus. Bremen, 3: 214

Especie mediterránea, repartida por el norte de África (Argelia y Túnez), Cerdeña y Oriente Próximo (Jordania e Israel).

Osmia (Helicosmia) aurulenta (Panzer, 1799)

Apis aurulenta Panzer, 1799. Fauna Ins. Germ. Initia: 60, no 22 Apis haematoda Panzer, 1801. Fauna Ins. Germ. Initia: 81, n 20

Osmia marginella Lepeletier, 1841. His. Nat. Ins. Hym., 2: 320 (partim)

Osmia tunensis, auctt. (non Fabricius, 1787)

Especie paleártica suroccidental, repartida por Gran Bretaña, Europa central y meridional, desde España en el área mediterránea hasta Turquía, Líbano en Oriente Próximo y Argelia en el norte de África.

Warncke (1988a) consideraba Osmia aurulenta como subespecie de Osmia tunensis.

Osmia (Helicosmia) caerulescens (Linnaeus, 1758)

Apis caerulescens Linnaeus, 1758. Syst. Nat., ed. 10, 1: 576.

Distribución holártica.

Osmia (Helicosmia) caerulescens caerulescens (Linnaeus, 1758)

Apis caerulescens Linnaeus, 1758. Syst. Nat., ed. 10, 1: 576

Apis aenea Linnaeus, 1761. Fauna Suecica, ed. 2: 421

Apis muraria Retzius, 17839. Caroli De Geer Gen. \& Spec. Ins.: 60 (non Geoffroy, 1785; nec Olivier, 1789)

Apis cuprea Geoffroy, 1785 in Fourcroy. Entomol. Parisiensis, 2: 447

Andrena cupraria Walckenaer, 1802. Faune Parisiensis, 2: 107 Osmia purpurea Cresson, 1864. Proc. Ent. Soc. Philadelphia, 3: 27 (non Pérez, 1895)

Osmia rustica Cresson, 1864. Proc. Ent. Soc. Philadelphia, 3: 37 (non Geoffroy, 1785)

Osmia dutti Cockerell, 1922. Ann. Mag. Nat. Hist., 10 (9): 266

La forma nominal se reparte por Europa, desde el norte, a través del territorio normediterráneo, incluida España, y por Asia Menor, el Cáucaso, Asia Central y EE.UU.

Osmia (Helicosmia) caerulescens cyanea (Fabricius, 1793) Andrena cyanea Fabricius, 1793. Ent. Syst., 2: 309

Esta subespecie se distribuye por Turquía en el área mediterránea oriental $\mathrm{y}$, en el norte de África, por Marruecos, Argelia, Túnez y Egipto.

\footnotetext{
Véase Alfken (1941), Schwarz et al. (1996) y Michener (2000) en relación con el nombre muraria Retzius, 1753.
} 
Osmia (Helicosmia) cinctella Dours, 1873

Osmia cinctella Dours, 1873. Revue Mag. Zool., 1 (3): 296

Especie distribuida por España, Creta y Argelia.

Warncke (1988a) consideraba esta especie como subespecie de Osmia sogdiana Morawitz, 1875.

Osmia (Helicosmia) clypearis Morawitz, 1871

Osmia clypearis Morawitz, 1871. Horae Soc. entomol. Ross., 8: 204

Osmia macedonica Tkalcu, 1979. Acta ent. Bohemoslov., 76: 323

Distribución mediterránea, por Grecia, Bulgaria, la antigua Yugoslavia y España, en Europa, más Turquía y el Cáucaso.

Osmia (Helicosmia) dimidiata Morawitz, 1870

Osmia dimidiata Morawitz, 1870. Horae Soc. entomol. Ross., 7: 316

Especie paleártica suroccidental, repartida por Europa central hasta el sur de Rusia y meridional, desde España hasta la Península Balcánica, por Asia Menor y Asia Central.

Osmia (Helicosmia) dimidiata dimidiata Morawitz, 1870 Osmia dimidiata Morawitz, 1870. Horae Soc. entomol. Ross., 7: 316

Subespecie distribuida por Europa suroriental, Asia Menor, Cáucaso y Asia Central.

Osmia (Helicosmia) dimidiata rossica Friese, 1899

Osmia rossica Friese, 1899. Ent. Nachr., 25: 64

Osmia taurica Radoszkowski, 1887. Horae Soc. entomol. Ross., 21: 285 (non Radoszkowski, 1874)

Subespecie distribuida por Europa central y meridional, desde España hasta la Península Balcánica y sur de Rusia.

Tkalcu (1975a) diferenciaba la subespecie Osmia dimidiata rossica de Europa central y meridional -desde España hasta la Península Balcánica y sur de Rusia-, que Warncke (1988a) interpretaba como variabilidad cromática. Rasmont et al. (1995) también separaban ambas poblaciones.

Osmia (Helicosmia) dives Mocsary, 1877

Osmia dives Mocsary, 1877. Term. Füzet., 1: 232

Descrita de Hungría, Cerdeña y sur de Francia, tiene distribución mediterránea occidental según van der Zanden (1988a).

Warncke (1988a) consideraba esta especie como Osmia sogdiana dives Mocsary, 1877, subespecie que localizaba en "la Península Balcánica, Hungría, Siria, Turquía, Oriente Próximo e Israel" y anteriormente Benoist (1931a) la contemplaba como una variedad de "Osmia vidua Gerst". Existe una cita antigua de Argelia
-2 hembras- (Saunders, 1908), que nadie ha vuelto a recoger.

Osmia (Helicosmia) dusmeti van der Zanden, 1998

Osmia (Chalcosmia) dusmeti van der Zanden, 1998. Linzer biol. Beitr., 30 (2): 525

Especie endémica de España.

Osmia (Helicosmia) heteracantha Pérez, 1895

Osmia heteracantha Pérez, 1895. Esp. nouv. Mellif. Barbarie: 12 Osmia frieseana Ducke, 1900. Ber. naturw-med. Ver. Innsbruck, 25: 249

Osmia sexsignata Benoist, 1950. Bull. Soc. Scienc.Nat. Maroc, 30: 44

Osmia aredeola Warncke, 1988. Entomofauna, 9: 19

Descrita de "Barbarie", se reparte por la Península Ibérica y el norte de África, desde Marruecos hasta Egipto.

También en este caso existe discrepancia en cuanto al reconocimiento de la especie y sus sinónimas: Warncke (1988a) consideraba Osmia heteracantha como subespecie de Osmia sogdiana, a la vez que establecía Osmia aredeola como una especie ibérica. Van der Zanden (1996) la pasaba a sinonimia. Por otro lado, para Mavromoustakis (1947) y Tkalcu (1975a), Osmia frieseana constituía una especie diferenciada del noroeste de África, o también para van der Zanden (1988a), pero en este caso de Marruecos.

Osmia (Helicosmia) labialis Pérez, 1879

Osmia labialis Pérez,1879. Act. Soc. Linn. Bordeaux, 33: 182

Existen distintas opiniones sobre el estatus de Osmia labialis, tanto como especie independiente, como considerada sinónima de Osmia melanogaster Spinola, 1808 -incluso, como ambas opciones simultáneamente- y sobre si presenta o no poblaciones subespecíficas (Tkalcu,1975a; van der Zanden, 1989; Rasmont et al. 1995; Schwarz et al., 1996; Schwarz \& Gusenleitner, 1999; Ebmer 2001, 2005).

Se ha citado de zonas alpinas de Europa central (en Francia, Suiza y Austria) y Rusia, y de cotas altas en el sur, incluidos los Pirineos franceses y españoles y otras sierras de la Península Ibérica, de la antigua Yugoslavia y de Túnez.

Osmia (Helicosmia) latreillei (Spinola, 1806)

Megachile latreillei Spinola, 1806. Insect. Ligur., 1: 31

Osmia nasidens Latreille, 1811. Encycl. méthod. Ins., 8: 578.

Osmia quadricornis Kriechbaumer, 1869. Verh. zool.-bot. Ges. Wien., 19: 600

Osmia friesei Verhoeff, 1892. Ent. Nachr., 18: 289

Especie distribuida por Europa central y sobre todo meridional, a través del territorio mediterráneo, desde España peninsular y el norte de África, incluidos Melilla, Marruecos y Argelia hasta Egipto y, en Oriente 
Próximo, Israel y Jordania, y conocida también de las Islas Canarias. Según Warncke (1988a) en Canarias, en las islas orientales, aparece la forma pálida de la especie -y también en Madeira- y en las islas occidentales de Canarias la forma nominal, de pubescencia marrón.

Por otro lado, para van der Zanden (1983, 1988a), Rasmont et al. (1995) y Warncke (1988a), Osmia nasidens es una especie válida. Es Warncke (1992b) quien establece la sinonimia ("la 우 de Niza, el neotipo..."), que Schwarz et al. (1996) recogen, ya que cuando Latreille (1811) describió la especie, lo hizo sin localidad tipo: "patria desconocida".

Osmia (Helicosmia) latreillei iberoafricana Peters, 1975

Osmia latreillei iberoafricana Peters, 1975. Senckenberg. biol, 56: 49

Subespecie con distribución mediterránea, cuyo territorio abarca desde España hasta Turquía y desde Marruecos hasta Israel, además de las islas Canarias y Madeira.

Osmia (Helicosmia) latreillei latreillei Spinola, 1806 Osmia latreillei Spinola, 1806. Insect. Ligur., 1: 31

Subespecie citada con diferencias de opinón (Warncke, 1988a; van der Zanden, 1988a; Tkalcu, 1975a, 2000) del área mediterránea occidental, Jordania en Oriente Próximo y Canarias, pero ausente de la Península Ibérica.

Osmia (Helicosmia) lazulina Benoist, 1928

Osmia lazulina Benoist, 1928. Bull. Soc. entomol. France, 33: 108

Especie repartida por Marruecos, Argelia y Túnez.

Osmia (Helicosmia) leaiana (Kirby, 1802)

Apis leaiana Kirby, 1802. Monogr. Apum Angliae, 2: 263

Distribución paleártica, por Europa, incluida España, hasta el Cáucaso y el norte de África.

Osmia (Helicosmia) leaiana leaiana (Kirby, 1802)

Apis hirta Geoffroy, 1785 in Fourcroy. Entomol. Parisiensis, 2: 444 (non Schrank, 1781)

?Apis ventralis Panzer, 1798. Fauna Ins. Germ. Initia: 56, n 20 Apis leaiana Kirby, 1802. Monogr. Apum Angliae, 2: 263

Osmia atra Schenck, 1853. Jahrb. Ver. Naturk. Nassau, 9: 182

Osmia confusa Morawitz, 1870. Horae Soc. entomol. Ross., 6 (1869): 38

Osmia Solskyi Morawitz, 1870. Horae Soc. entomol. Ross., 7: 317 Osmia truncatula Thomson, 1872. Hym. Scand., 2: 239

Osmia bidens Pérez,1879. Act. Soc. Linn. Bordeaux, 33: 181

Osmia forsii Alfken, 1924. Notul. ent., 4: 37

Osmia aduncoides Strand, 1910. Ent. Zeit., 24: 216 (partim)

Subespecie distribuida por Europa central y Gran Bretaña, hasta Rusia en el norte y zonas altas del sur de Europa, incluidas algunas sierras españolas, Pirineos franceses, Alpes italianos, Turquía y Armenia, por el este, y en el norte de África por Argelia y Túnez.

Osmia (Helicosmia) leaiana schachti Warncke, 1988

Osmia ventralis schachti Warncke, 1988. Entomofauna, 9: 31

Subespecie endémica de Marruecos.

Osmia (Helicosmia) melanogaster Spinola, 1808

Osmia melanogaster Spinola, 1808. Insect. Ligur., 2: 63

Distribuida por zonas templadas de Europa central y meridional.

En relación con las formas de Osmia melanogaster no existe un criterio uniforme entre los especialistas. Por ejemplo, Warncke (1988a) diferenciaba de la subespecie nominal -a la que asignaba una distribución sureuropea- la subespecie subaenea Pérez, 1895 para la población norteafricana y del Oriente Próximo. Tkalcu (1974b), previamente, había considerado independientemente a Osmia subaenea Pérez, 1895, distribuida por España y el norte de África. Por otro lado, van der Zanden (1988a) y Rasmont et al. (1995), de la subespecie nominal de Osmia melanogaster sólo separaban una forma distinta de Suiza, la subespecie carniolica Morawitz, 1872, que Warncke (1988a) y Schwarz et al. (1996) incluían como sinónima de Osmia melanogaster. $\mathrm{Si}$ se tiene en cuenta, además, que tanto Warncke (1988a) como Schwarz et al. (1996) incluían también entre las sinónimas de Osmia melanogaster a Osmia labialis, especie bien fundamentada para van der Zanden (1989) y Rasmont et al. (1995), se comprenderá que sólo un estudio amplio del material de todas estas formas podrá resolver la cuestión.

Osmia (Helicosmia) melanogaster melanogaster Spinola, 1808

Osmia melanogaster Spinola, 1808. Insect. Ligur., 2: 63

Osmia aterrima Morawitz, 1872. Verh. zool.-bot. Ges. Wien., 22: 357

Osmia carniolica Morawitz, 1872. Verh. zool.-bot. Ges. Wien., 22: 358

Osmia incerta Radoszkowski, 1876. Horae Soc. entomol. Ross., 12: 113

Osmia notata, auctt. (non Fabricius, 1804)

La subesepcie nominal se reparte por las zonas templadas de Europa central e Italia, Sicilia, Bulgaria y Croacia, en el entorno mediterráneo.

Osmia (Helicosmia) melanogaster subaenea Pérez, 1895 Osmia subaenea Pérez, 1895. Esp. nouv. Mellif. Barbarie: 11

Subespecie distribuida por Europa suroccidental, por España, Francia, Sicilia, por Turquía y por la zona noroccidental de África hasta el Sahara.

Tkalcu (1974b, 1975a) consideraba a Osmia subaenea una especie diferenciada. 
Osmia (Helicosmia) nasoproducta Ferton, 1910

Osmia nasoproducta Ferton, 1910. Ann. Soc. entomol. France, 78: 406

Especie descrita de Córcega y citada más tarde de España, Italia y Francia continental.

Osmia (Helicosmia) niveata (Fabricius, 1804)

Apis fulviventris Panzer, 1798. Fauna Ins. Germ. Initia: 56, n 18 (non Scopoli, 1783)

Anthophora niveata Fabricius, 1804. Syst. Piezator: 377

Apis fulvicornis Latreille, 1809 in Dalla Torre, 1896. Cat.

Hym., 10: 396, grafía incorrecta

Osmia minuta Bramson, 1879. Bull. Soc. Imp. Nat. Moscou, 54: 292

Osmia sieversi Morawitz, 1886. Horae Soc. entomol. Ross., 20 (1885-1887): 74

Osmia carneiventris Radoszkowski, 1887. Horae Soc. entomol. Ross., 21: 286

Osmia fulviventris var. albiscopa Alfken, 1913. Bull. Soc. ent. Belg., 22: 202 (partim)

Osmia fulviventris albiscopa Alfken, 1914. Bull. Soc. ent. Belg., 22: 202

Especie paleártica occidental, repartida por Europa de norte a sur, incluidas la Península Ibérica, Baleares y Azores, el norte de África, desde Marruecos a Egipto, el territorio mediterráneo, Canarias y Madeira, Asia Menor, el Cáucaso y Asia Central.

Osmia (Helicosmia) niveibarbis Pérez, 1902

Osmia niveibarbis Pérez, 1902. Proc. ver. Soc. Linn. Bordeaux, 57: 64

Osmia tarfensis Saunders, 1908. Trans. ent. Soc. London: 246

Especie mediterránea occidental, distribuida por el norte de África (Marruecos, Argelia y Túnez), Sicilia y Cerdeña en el norte del Mediterráneo, y citada también del sur de España e Italia continental.

Van der Zanden (1988a) sitúa a Osmia tarfensis como sinónima de Osmia cinctella.

\section{Osmia (Helicosmia) niveocincta Pérez, 1879}

Osmia niveocincta Pérez, 1879. Act. Soc. Linn. Bordeaux, 33: 184 Osmia violascens Pérez, 1895. Esp. nouv. Mellif. Barbarie: 12

Especie mediterránea, repartida en Europa por España, Francia e Italia y, en el norte de África, por Argelia y Egipto.

Warncke (1988a) considera a Osmia niveocincta como subespecie de Osmia sogdiana. Por otro lado, para van der Zanden (1988a) y Rasmont et al. (1995), Osmia violascens es una especie válida.

Osmia (Helicosmia) notata (Fabricius, 1804)

Anthophora notata Fabricius 1804. Syst. Piez.: 376

Pseudosmia decemsignata Radoszkowski, 1874. Bull. Soc. Imp. Nat. Moscou, 48 (1): 159

Osmia laterefasciata Costa, 1884. Rendic. Accad. Sc. fis. mat. Napoli, 23: 169
Especie distribuida por el sur de Europa (incluyendo a España, Portugal, Córcega, Cerdeña, Malta, Italia), el norte de África (Marruecos, Argelia, Libia, Egipto) y por Asia Central.

Osmia (Helicosmia) signata Erichson, 1835

Osmia signata Erichson, 1835. En: Waltl, Reise d'Tyrol, 2: 107

Especie paleártica occidental, distribuida por Europa central, el territorio mediterráneo, desde Portugal y España hasta Croacia, en el sur de Europa, Argelia y Egipto en el norte de África, Oriente Próximo y Asia Central.

Existe discrepancia en cuanto al reconocimiento de las subespecies o la situación sinonímica (Stanek, 1964; van der Zanden, 1984; Warncke, 1988a; Rasmont et al., 1995).

Osmia (Helicosmia) signata laticincta Pérez, 1879

Osmia laticincta Pérez, 1879. Act. Soc. Linn. Bordeaux, 33: 177

Subespecie de España peninsular y Baleares, Rodas en Grecia, Chipre y Palestina en Oriente Próximo.

Para Warncke (1988a) esta subespecie es sinónima de la nominal.

Osmia (Helicosmia) signata signata Erichson, 1835

Osmia melanippa Spinola 1808. Ins. Ligur., 2: 66 (no disponible) Osmia signata Erichson, 1835. En: Waltl, Reise d'Tyrol, 2: 107 Osmia jucunda Smith, 1853. Cat. Brit. Hym. Brit. Mus., 1: 139 Osmia vidua Gerstaecker, 1869. Stettin. ent. Ztg., 30: 345 Osmia cincta Dours, 1873. Revue Mag. Zool., 1 (3): 295

Osmia atriventris Costa, 1883. Atti. Accad. Sc. fis. mat. Napoli, (2) 1 (2): 95 (non Cresson, 1864)

Osmia costaniana Dalla Torre \& Friese, 1895. Ent. Nachr., 21: 70

Subespecie mediterránea, repartida desde España (y Portugal, según una antigua y dudosa cita de Dusmet [1921]), hasta Croacia y el noroeste de África.

Osmia (Helicosmia) sinuata Pérez, 1895

Osmia sinuata Pérez, $1895^{10}$. Esp. nouv. Mellif. Barbarie: 17 Osmia rufiscopa Friese, 1899. Ent. Nachr., 25: 26

Descrita de "Barbarie", esta especie se conoce de Argelia, Marruecos y Siria.

Van der Zanden (1988a, 1992a) incluía la especie como Anthocopa (Anthocopa) sinuata (Pérez, 1895).

Osmia (Helicosmia) subcornuta Morawitz, 1875

Osmia subcornuta Morawitz, 1875. En: Fedtschenko, Izv. Imp. Obshch. Ljubit. Estest. Antrop. Etnog., 19: 79

Osmia rubicola Friese, 1891. Ent. Nachr., 17: 257 (non Pérez, 1890)

Especie con distribución en el área mediterránea oriental, desde Italia hasta Turquía, Líbano e Israel, en Oriente Próximo, y Turkestán.

10 Rasmont et al. (1995) incluían como sinonimia a "Osmia diversa Friese, (nomen nudum)", que no se ha podido localizar al no constar otros datos en la referencia. 
Osmia (Helicosmia) tunensis (Fabricius, 1787)

Apis tunensis Fabricius, 1787. Mant. Ins, 1: 304

Anthophora tunensis Fabricius, 1804. Syst. Piezator: 376

Osmia pseudoaurulenta Dours, 1873. Revue Mag. Zool., 1 (3): 295

Osmia dissimilis Friese, 1899. Ent. Nachr., 25 (4): 63

Especie distribuida por España peninsular, Portugal y Sicilia en Europa, y Marruecos, Melilla, Argelia, Túnez y Egipto en el norte de África.

Subgénero Hemiosmia Tkalcu, 1975

Osmia (Hemiosmia) Tkalcu, 1975. Acta ent. Bohemoslov., 72: 34 EsPeCIE TIPO: Osmia argyropyga Pérez, 1879 por designación original

Osmia (Exosmia) Tkalcu, 1979. Acta ent. Bohemoslov., 76: 321 ESPECIE TIPO: Osmia difficilis Morawitz, 1875, por designación original

Distribución por el área mediterránea y desde Asia oriental hasta Asia Central; Michener (2000) le asignaba 6 especies.

Haeseler (2005) revisaba el subgénero Hemiosmia y establecía una nueva especie, Osmia chrysolepta Haeseler, 2005, para la hasta entonces población oriental de Osmia balearica Schmiedeknecht, 1885, de Israel, Jordania y "(?) Egipto", y consideraba Exosmia como un subgénero válido. Otros ajustes en la distribución se incluyen en las especies siguientes.

Osmia (Hemiosmia) argyropyga Pérez, 1879

Osmia argyropyga Pérez, 1879. Act. Soc. Linn. Bordeaux, 33: 175 Osmia entoprocta Pérez, 1879. Act. Soc. Linn. Bordeaux, 33: 179

Descrita de Marsella, sur de Francia, esta especie aparece además en España, Italia y Marruecos.

Osmia (Hemiosmia) balearica Schmiedeknecht, 1885

Osmia balearica Schmiedeknecht, 1885. Apidae Europaeae, 2 (11): 902,918

Especie distribuida por España y Sicilia en Europa y por Marruecos y Túnez en el norte de África.

Osmia (Hemiosmia) iberica van der Zanden, 1987

Osmia (Exosmia) iberica van der Zanden, 1987. Reichenbachia, 25 (16): 73

Osmia difficilis clanga Warncke, 1988. Entomofauna, 9: 398

Especie sólo conocida de España, Portugal y Grecia.

Osmia (Hemiosmia) uncicornis Pérez, 1895

Osmia uncicornis Pérez, 1895. Esp. nouv. Mellif. Barbarie: 10 Osmia anceps Pérez, 1895. Esp. nouv. Mellif. Barbarie: 11

Esta especie, descrita de "Barbarie", aparece en la Península Ibérica y en el norte de África, donde sólo está presente en Marruecos (Haeseler, 2005).
Subgénero Melanosmia Schmiedeknecht, 1885

Osmia (Melanosmia) Schmiedeknecht, 1885. Apidae Europaeae, 2 (11): 885

ESPECIE TIPO: Osmia fuciformis Latreille, $1811=$ Osmia xanthomelana (Kirby, 1802) = Apis xanthomelana Kirby, 1802, por designación de Sandhouse, 1939

Nothosmia Ashmead. 1899. Trans. Am. Entomol. Soc., 26: 75 EsPeCIE TIPO: Osmia distincta Cresson, 1864, por designación original

Centrosmia Robertson, 1903. Trans. Am. Entomol. Soc., 29: 165,170

ESPECIE TIPO: Osmia bucephala Cresson, 1864, por monotipia y designación original

Leucosmia Robertson, 1903. Trans. Am. Entomol. Soc., 29: 166, 171

ESPECIE TIPO: Osmia albiventris Cresson, 1864, por monotipia y designación original

Xanthosmia Robertson, 1903. Trans. Am. Entomol. Soc., 29: 166,171

ESPECIE TIPO: Osmia cordata Robertson, 1902, por monotipia y designación original

Monilosmia Robertson, 1903. Trans. Am. Entomol. Soc., 29: 166,171

ESPECIE TIPO: Osmia canadensis Cresson, $1864=$ Osmia simillima Smith, 1853, por monotipia y designación original

Chenosmia Sinha, 1958. Univ. Kansas Scien. Bull., 39:233

ESPECIE TIPO: Osmia penstemonis Cockerell, 1906, por designación original

Distribución holártica; Michener (2000) le asignaba 17 especies.

Osmia (Melanosmia) alticola Benoist, 1922

Osmia alticola Benoist, 1922. Bull. Soc. entomol. France: 323

Especie de tendencia orófila, distribuida en los Alpes, suizos y austríacos, y los Pirineos en ambas vertientes, francesa y española. Existe alguna cita antigua (Mavromoustakis, 1947; Ceballos, 1956) de más al interior de España, que requeriría confirmación.

Osmia (Melanosmia) inermis (Zetterstedt, 1838)

Anthophora (Osmia) inermis Zetterstedt, 1838. Ins. Lappon., 1: 466 (partim)

Anthophora (Osmia) angustula Zetterstedt, 1838. Ins. Lappon., 1: 466 (partim)

Osmia globosa Cresson, 1864. Proc. Ent. Soc. Philadelphia, 3: 36 (non Scopoli, 1763)

Osmia vulpecula Gerstaecker, 1869. Stettin. ent. Ztg., 30: 335

Osmia globosiformis Cockerell, 1910. Canad. Entomol., 42: 311

Especie holártica. Ebmer (2003) le asignaba en Europa "distribución bóreoalpina de los Alpes, Austria y Suiza", pero existen otras citas (Mavromoustakis, 1947; Ceballos, 1956; Tkalcu, 1983; Warncke, 1988a) de Centroeuropa -Checoslovaquia-, Bélgica, Alemania, Francia y de distintas sierras ibéricas, en el sur.

Osmia (Melanosmia) nigriventris (Zetterstedt, 1838)

Anthophora nigriventris Zetterstedt, 1838. Insecta lapponica descripta, 1: 465

Osmia frigida Smith, 1853. Cat. Brit. Hym. Brit. Mus., 1: 142 
Osmia hudsonica Cresson, 1864. Proc. Ent. Soc. Philadelphia, 3: 21

Osmia baicalensis Radoszkowski, 1868. Horae Soc. entomol. Ross., 5 (1867-1868): 80

Osmia corticalis Gerstaecker, 1869. Stettin. ent. Ztg., 30: 331

Distribución holártica, que aparece en Siberia (citada de Baikalia) y en Europa se conoce del norte y el centro, ampliamente repartida por los Alpes suizos, austríacos e italianos y llega a Francia.

Osmia (Melanosmia) parietina Curtis, 1928

Anthophora (Osmia) angustula Zetterstedt, 1838. Ins. Lappon., 1: 466 (partim)

Osmia vankowitzii Radoszkowski, 1887. Horae Soc. entomol. Ross., 21: 283 (no disponible)

Osmia parietina Curtis, 1928. British Entomol., 5: 222

Osmia hyperborea Tkalcu, 1983. Vêst. cs. Spolec. zool., 47: 156

Especie paleártica occidental con tendencia orófila, repartida a lo largo de Europa, que en el sur llega hasta el centro de España y la Península Balcánica, y en el Cáucaso, en Asia.

Osmia (Melanosmia) pilicornis Smith, 1846

Osmia pilicornis Smith, 1846. Zoologist, 4:1567

Especie distribuida en Europa occidental, desde el norte hasta Francia en el sur.

Osmia (Melanosmia) recta Pérez, 1902

Osmia recta Pérez, 1902. Proc. ver. Soc. Linn. Bordeaux, 57: 63

Especie endémica de Argelia.

Osmia (Melanosmia) uncinata Gerstaecker, 1869

Anthophora (Osmia) inermis Zetterstedt, 1838. Ins. Lappon., 1: 466 (partim)

Osmia uncinata Gerstaecker, 1869. Stettin. ent. Ztg., 30: 336

Osmia laticeps Thomson, 1872. Hym. Scand., 2: 242 (non Friese, 1899)

Osmia svenssoni Tkalcu 1983. Vêst. cs. Spolec. zool., 47: 154

Especie distribuida en Europa occidental, desde el norte hasta Francia e Italia en el sur.

Osmia (Melanosmia) xanthomelana (Kirby, 1802)

Apis xanthomelana Kirby, 1802. Monogr. Apum Angliae, 2: 246 Osmia fuciformis Latreille, 1811. Encycl. méthod. Ins., 8: 579 Osmia chrysomelina Panzer, 1812. Fauna Ins. Germ. Initia: $110, \mathrm{n}^{\mathrm{o}} 15$

Osmia atricapilla Curtis, 1828. British Entomol., 5: 223

Distribución eurasiática: desde Siberia, en el norte, se reparte a través de Europa central y meridional, incluidos España, Francia, norte de Italia y la Península Balcánica.

Osmia (Melanosmia) xanthomelana clarior Tkalcu, 1983 Diphysis pyrenaica Lepeletier, 1841. His. Nat. Ins. Hym., 2: 308, (partim)
Osmia (Melanosmia) xanthomelana clarior Tkalcu, 1983. Vêst. cs. Spolec. zool., 47: 152

Subespecie conocida sólo de España y Francia.

Osmia (Melanosmia) xanthomelana xanthomelana (Kirby, 1802)

Apis xanthomelana Kirby, 1802. Monogr. Apum Angliae, 2: 246

Subespecie europea, distribuida desde Europa septentrional y media, incluida Gran Bretaña, hasta Europa meridional. Existen citas ibéricas (Ceballos, 1956; Pérez-Íñigo, 1984) cuya pertenencia a la forma nominal debería ser confirmada.

Subgénero Metallinella Tkalcu, 1966

Metallinella Tkalcu, 1966. Acta ent. Bohemoslov., 63: 200

ESPECIE TIPO: Osmia atrocaerulea Schilling, $1849=$ Eucera brevicornis Fabricius, 1798, por designación original.

Distribución desde Europa central al área mediterránea, y en ésta, desde España hacia el este, y por Uzbekistán, en Asia Central; Michener (2000) le asignaba una sola especie.

Michener (2000) rechazaba su estatus de género por las mandíbulas hendidas de las hembras, al considerar que se trata de una regresión, pero, no obstante, véanse Tkalcu (1966), Warncke (1991d) o Rasmont et al. (1995) para otras opiniones sobre Metallinella.

En el área mediterránea occidental existen dos subespecies, y una tercera -leucogastra Morawitz, 1875- se distribuye por la parte más oriental, Oriente Próximo y Asia Central.

Osmia (Metallinella) brevicornis (Fabricius, 1798)

Eucera brevicornis Fabricius, 1798. Ent. Syst., suppl.: 278

Especie distribuida por Europa central y sur y la zona noroccidental de África.

Osmia (Metallinella) brevicornis brevicornis (Fabricius, 1798)

Eucera brevicornis Fabricius, 1798. Ent. Syst., suppl.: 278 Osmia atrocaerulea Schilling, 1849. Übers Arbeit schles. Ges. f. vaterl. Kultur 1848: 101

Osmia panzeri Morawitz, 1870. Horae Soc. entomol. Ross., 6 (1869): 65

Subespecie repartida por Europa central y meridional, incluida España, y por el este, en Crimea.

Osmia (Metallinella) brevicornis subcyanea (Alfken, 1936)

Osmia atrocaerulea var. cyanella Alfken, 1931. Stettin. ent. Ztg., 92: 57 (no disponible)

Osmia atrocaerulea var. subcyanea Alfken, 1936. Veröff. $d t$. Kolon. u.Übersee-Mus. Bremen, 1 (3): 316

Subespecie distribuida por Marruecos y Argelia. 
Subgénero Monosmia Tkalcu, 1974

Osmia (Monosmia) Tkalcu, 1974. Beitr. Ent., Berlin, 24(5/8): 339 ESPECIE TIPO: Osmia apicata Smith, 1853, por monotipia y designación original

Distribución mediterránea oriental, en Asia Menor y el Cáucaso; Michener (2000) le asignaba sólo una especie.

Osmia (Monosmia) apicata Smith, 1853

Osmia apicata Smith, 1853. Cat. Brit. Hym. Brit. Mus., 1: 140 Osmia macroglossa Gerstaecker, 1869. Stettin. ent. Ztg., 30: 349

Especie con distribución principalmente mediterránea oriental, por Italia y la Península Balcánica, Asia Menor y el Cáucaso.

Subgénero Neosmia Tkalcu, 1974

Osmia (Neosmia) Tkalcu, 1974. Beitr. Ent., Berlin, 24(5/8): 333 ESPECIE TIPO: Osmia gracilicornis Pérez, 1895, por designación original

Distribución paleártica suroccidental por Europa, incluidas las Islas Británicas, las Canarias, y el área mediterránea hasta Israel, en Oriente Próximo; Michener (2000) le asignaba 8 especies.

Osmia (Neosmia) bicolor (Schrank, 1781)

? Apis fusca Scopoli, 1763. Entomol. Carniol.: 303

Apis bicolor Schrank, 1781. Enum. Ins. Austr.: 400

Apis rustica Geoffroy in Fourcroy, 1785. Entomol. Parisiensis, 2: 451

? Apis fusca Christ, 1791. Naturg. der Insecten: 182 (non Scopoli, 1763) (nomen oblitum)

Osmia pyrenaea Lepeletier, 1841. Hist. Nat. Ins. Hym., 2: 319 Osmia fusca Gistel, 1857. Vacuna, 2: 537

Osmia rufitarsis Smith, 1879. Descr. New. Spec. Hymen.: 61

Osmia monachiensis Strand, 1917. Archiv. f. Naturg., 82A (5):

98 (nomen novum para Osmia fusca Gistel, 1857)

Especie distribuida por Europa central, zona meridional del norte y en el sur por zonas montañosas, incluidas citas de España y Portugal, el sur de Urales y Cáucaso.

Osmia (Neosmia) cinnabarina Pérez, 1895

Osmia cinnabarina Pérez, 1895. Esp. nouv. Mellif. Barbarie: 10

Descrita de "Barbarie", esta especie se distribuye por Argelia, en el norte de África, y las Islas Canarias.

Osmia (Neosmia) gracilicornis Pérez, 1895

Osmia gracilicornis Pérez, 1895. Esp. nouv. Mellif. Barbarie: 10

Descrita de "Barbarie", esta especie se reparte en el norte de África por Melilla, Marruecos, Argelia y Túnez.

Osmia (Neosmia) purpurata Ducke, 1900

Osmia purpurata Ducke, 1900. Ber. naturw-med. Ver. Innsbruck, 25: 134

Especie endémica de Argelia.
Osmia (Neosmia) rufigastra Lepeletier, 1841

Osmia rufigastra Lepeletier, 1841. Hist. Nat. Ins. Hym., 2: 324

Especie distribuida en el norte de África, por Melilla, Marruecos, Argelia y Túnez.

Osmia (Neosmia) scutispina Gribodo, 1894

Osmia scutispina Gribodo, 1894. Boll. Soc. entomol. Ital., 26: 102

Osmia rosea Friese, 1921. D. Ent. Z. 1920: 50

Especie conocida de Argelia, Túnez y Egipto.

Osmia (Neosmia) tingitana Benoist, 1969

Osmia tingitana Benoist, 1969. Bull. Soc. Scienc. Nat. Maroc, 74: 243

Osmia tkalcui Peters, 1977. Ent. Zeit., 87: 22, 25

Especie distribuida en el norte de África, por Marruecos, Argelia, Libia y Egipto.

\section{Subgénero Osmia Panzer, 1806}

Distribución holártica, desde Europa occidental hasta Japón, África desde el sur al norte y Pakistán; Michener (2000) le asignaba unas 20 especies paleárticas.

Osmia (Osmia) cerinthidis Morawitz, 1876

Osmia cerinthidis Morawitz, 1876. Horae Soc. entomol. Ross., 12: 41

La localización de esta especie -Europa central, Asia Menor e Irán- no está bien aclarada y hay distintas opiniones (Peters, 1978; van der Zanden, 1988a; Rasmont et al., 1995; Schwarz et. al., 1996; Schwarz \& Gusenleitner, 1999; Westrich, 1999; Ebmer, 2001). No obstante, Ebmer (2001) confirmaba, en Europa, las citas de Alemania, Austria, Grecia y Turquía.

Osmia (Osmia) cerinthidis crassiclypeata Peters, 1978

Osmia cerinthidis crassiclypeata Peters, 1978. Senckenberg. biol., 58 (5-6): 299

Esta subespecie, endémica de Sicilia, parece ser la única localizada en el área mediterránea occidental.

Osmia (Osmia) cornuta (Latreille, 1805)

Megachile cornuta Latreille, 1805. Hist. nat. Crust. Ins., 14: 59

Especie distribuida por Europa central y meridional y el norte de África.

Existen distintas subespecies, de modo que a la forma nominal le corresponde la distribución anterior y concretamente, en el sur de Europa, aparece en España, Sicilia y Grecia y, en el norte de África, en Túnez. Además existen otras tres poblaciones diferenciadas, en Chipre, Egipto e Irán y Turkestán (Peters, 1978; van der Zanden, 1988a). 
Osmia (Osmia) emarginata Lepeletier, 1841

Osmia emarginata Lepeletier, 1841. His. Nat. Ins. Hym., 2: 317

Especie paleártica occidental, repartida por Europa central y meridional, Marruecos y Argelia, en el norte de África, Palestina y Líbano en Oriente Próximo, y el Cáucaso.

Osmia (Osmia) emarginata emarginata Lepeletier, 1841 Osmia emarginata Lepeletier, 1841. His. Nat. Ins. Hym., 2: 317

Esta subespecie presenta distribución por Europa central y meridional, el norte del territorio mediterráneo, desde España y Francia hasta Palestina, Líbano en Oriente Próximo, y el Cáucaso.

Osmia (Osmia) emarginata infuscata Peters, 1978

Osmia emarginata var. fusca Benoist, 1928. Bull. Soc. entomol. France, 33: 215 (non Christ, 1791; nec Gistel, 1857)

Osmia emarginata infuscata Peters, 1978. Senckenberg. biol., 58: 310

Subespecie distribuida en Marruecos (en el Atlas) y en Argelia.

Osmia (Osmia) kohlii Ducke, 1900

Osmia kohlii Ducke, 1900. Ber. naturw-med. Ver. Innsbruck, 25: 271

Descrita de Sicilia, se ha citado, sin confirmación posterior, de Argelia (Stanek, 1964), sólo del sur de Italia, Sicilia y Malta (van der Zanden, 1988a) y sólo de Córcega (Rasmont et al., 1995).

Osmia (Osmia) lignaria Say, 1837

Osmia lignaria Say, 1837. Boston. Tour. Nat. Hist, 1: 399 Osmia purpurascens Smith, 1849 Zoologist, 7: appendix lviii Osmia lignaria var. alpina Cockerell, 1900. Ann. Mag. Nat. Hist., 5 (7): 409

Se trata de una especie americana (Rust, 1974), introducida en España en la década de los años 70 del siglo $\mathrm{XX}$, que uno de los autores (F. Torres leg.) encontró naturalizada y cuyos datos inéditos corresponden a individuos de la subespecie Osmia lignaria propinqua Cresson, 1864.

Osmia (Osmia) lignaria propinqua Cresson, 1864

Osmia lignaria propinqua Cresson, 1864: Proc. Ent. Soc. Philadelphia, 3: 23.

Subespecie americana, que en Europa se conoce exclusivamente de España, de la provincia de Zamora (Corrales del Vino, 12-V-1990, F. Torres leg.) a partir de un nido con 5 machos y una hembra. No se tiene referencia de capturas o citas posteriores.

Osmia (Osmia) mustelina Gerstaecker, 1869

Osmia mustelina Gerstaecker, 1869. Stettin. ent. Ztg., 30: 348
Osmia emarginata var. griseohirta Alfken, 1935. Mitt. ent. Ver. Bremen, 23: 23

Osmia emarginata, auctt. (non Lepeletier, 1841)

Especie distribuida por Europa central, el área mediterránea oriental desde Italia y Sicilia, incluido Israel, y por el Cáucaso e Irán. La forma nominal se reparte por Suiza, Alemania, Turquía e Israel.

Osmia (Osmia) mustelina umbrosa Peters, 1978

Osmia umbrosa Peters, 1978. Senckenberg. biol., 58: 313

Subespecie endémica de Italia, incluida Sicilia.

Osmia (Osmia) proboscidea Benoist, 1950

Osmia proboscidea Benoist, 1950. Bull. Soc. entomol. France, 55: 101

Especie endémica de Marruecos, conocida sólo del Atlas Medio.

Osmia (Osmia) rufa (Linnaeus, 1758)

Apis rufa Linnaeus, 1758. Syst. Nat., ed. 10, 1: 575 (non Scopoli, 1763)

Especie con distribución paleártica, en Europa, Asia Menor, Irán y en el norte de África.

Hay ciertas discrepancias en cuanto a las citas y localización de las subespecies de Osmia rufa y la consideración de sus sinónimas. Véanse, por ejemplo, Mavromoustakis (1948), Tkalcu (1974b), Peters (1978), van der Zanden (1984, 1988a), Rasmont et al.(1995) o Standfuss et al. (2003).

Según Peters (1978) y van der Zanden (1988a), en la Península Ibérica coexisten la subespecie nominal y Osmia rufa cornigera (Rossi, 1790), que incluso se solapan y dan individuos híbridos en el norte. Igualmente, Peters (1978) reconocía Osmia rufa fracticornis Pérez, 1895 en la isla de Mallorca, en Baleares.

Osmia (Osmia) rufa cornigera (Rossi, 1790)

Apis cornigera Rossi, 1790. Fauna Etrusca, 2: 108 (non Kirby, 1802)

Apis fronticornis Panzer, 1799. Fauna Ins. Germ. Initia: 63, nº 20

Subespecie distribuida por Europa, incluida España, Asia Menor e Irán.

Osmia (Osmia) rufa fracticornis Pérez, 1895

Osmia fracticornis Pérez, 1895. Esp. nouv. Mellif. Barbarie: 10

Descrita de "Barbarie", esta subespecie se distribuye en el norte de África por Marruecos, Argelia y Túnez y por la isla de Mallorca en España.

Osmia (Osmia) rufa rufa (Linnaeus, 1758)

Apis rufa Linnaeus, 1758. Syst. Nat., ed. 10, 1: 575 (non Scopoli, 1763)

Apis bicornis Linnaeus, 1758. Syst. Nat., ed. 10, 1: 575 
Apis agino Harris, 1776. Expos. English. Insects: 162, Tab 49, Fig. 7

Osmia hedera Smith, 1844. Zoologist, 2: 747

Osmia rufa var. borealis Ducke, 1899. Ent. Nachr., 25: 215

Subespecie europea; en el sur se ha citado en la Península Íberica, con más o menos verosimilitud (Ceballos, 1956; Vergés, 1964; Peters, 1978; Pérez-Íñigo, 1984; van der Zanden, 1988a; Le Goff, com. per.), Córcega (Rasmont et al., 1995) y Grecia (Standfuss et al., 2003).

Osmia (Osmia) tricornis Latreille, 1811

Osmia tricornis Latreille, 1811. Encycl. méthod. Ins., 8: 575

Especie sureuropea, incluidos Francia, Italia y España, con las islas Canarias, y en el norte de África, Melilla, Marruecos, Argelia y Túnez.

\section{Subgénero Pyrosmia Tkalcu, 1975}

Osmia (Pyrosmia) Tkalcu, 1975. Acta rer. natur. Mus. nat Slov., Bratislava, 21: 182

EsPECIE TIPO: Osmia ferruginea Latreille, 1811, por designación original

Osmia (Viridosmia) Warncke, 1988. Entomofauna, 9: 5

ESPECIE TIPO: Osmia saxicola Ducke, 1899, por designación original

Osmia (Caerulosmia) van der Zanden, 1988. Zool. Med., 62: 123 (nomen nudum)

Osmia (Caerulosmia) van der Zanden, 1989. Entomol. Abh Mus. Tierkd. Dresden, 53 (6): 83

EsPeCIE TIPO: Osmia gallarum Spinola, 1808, por designación original

Distribución en Europa central y meridional, toda el área mediterránea y hasta la India y Mongolia; Michener (2000) le asignaba 33 especies.

Osmia (Pyrosmia) amathusica Mavromoustakis, 1937

Osmia amathusica Mavromoustakis, 1937. Ann. Mag. Nat. Hist., 20 (10): 522

Especie mediterránea oriental, repartida en Italia, Grecia, Chipre, Turquía y en Siria y Jordania, en Oriente Próximo.

Osmia (Pyrosmia) cephalotes Morawitz, 1870

Osmia cephalotes Morawitz, 1870. Horae Soc. entomol. Ross., 7: 315 (non Pérez, 1879)

Especie distribuida en el sur de Europa, norte de África, Cáucaso y Kopet-Dagh, en Asia Central.

Osmia (Pyrosmia) cephalotes cephalotes Morawitz, 1870 Osmia cephalotes Morawitz, 1870. Horae Soc. entomol. Ross., 7: 315 (non Pérez, 1879)

Osmia pulsata Buysson, 1899. Ann. Soc. entomol. France, 68: 668

Subespecie distribuida por el sur de Francia, Italia y la Península Ibérica, en Europa y en Marruecos, Argelia y Túnez, en el norte de África.
Osmia (Pyrosmia) cephalotes longiceps Morawitz, 1876

Osmia longiceps Morawitz, 1876. Horae Soc. entomol. Ross., 12: 40

Osmia bacillus Pérez, 1879. Act. Soc. Linn. Bordeaux, 33: 203

Subespecie distribuida desde Italia, por el territorio mediterráneo nororiental, hasta Israel y en Armenia, el Cáucaso y Kopet-Dagh, en Asia Central.

Standfuss et al. (2003) le otorgaban rango específico.

\section{Osmia (Pyrosmia) cyanoxantha Pérez, 1879}

Osmia cyanoxantha Pérez, 1879. Act. Soc. Linn. Bordeaux, 33: 185 Osmia cyanura van der Zanden, 1991. Linzer biol. Beitr., 23 (1): 53

Osmia elbaba Warncke, 1992. Linzer biol. Beitr., 24 (2): 904

Especie distribuida en Marruecos, Argelia y Túnez, en el norte de África, en el sur de Europa, desde la Península Ibérica hasta Turquía, y en Siria y Jordania, en Oriente Próximo.

\section{Osmia (Pyrosmia) derasa Pérez, 1895}

Osmia derasa Pérez, 1895. Esp. nouv. Mellif. Barbarie: 12 Osmia pseudoderasa Benoist, 1950. Bull. Soc. Scienc. Nat. Maroc, 30: 184

Especie descrita de "Barbarie", que se distribuye en el norte de África, en Marruecos, Túnez, Argelia y Libia.

Osmia (Pyrosmia) derasa derasa Pérez, 1895

Osmia derasa Pérez, 1895. Esp. nouv. Mellif. Barbarie: 12

Subespecie repartida por Marruecos, Argelia y Túnez.

Osmia (Pyrosmia) derasa violetta Warncke, 1992

Osmia derasa violetta Warncke, 1992. Linzer biol. Beitr., 24 (2): 905

Subespecie endémica de Túnez.

Osmia (Pyrosmia) ferruginea Latreille, 1811

Osmia ferruginea Latreille, 1811. Encycl. méthod. Ins., 8: 579 Osmia metallica Lucas, 1849. Expl. Sci. ent., Algerie, 3: 191. Osmia igneopurpurea Costa, 1882. Rendic. Accad. Sc. fis. mat. Napoli, 21 (10): 198

Descrita de Egipto, esta especie se encuentra distribuida por Europa meridional, el sur de Francia, incluida Cerdeña, España, Portugal y Chipre, y el norte de África (Melilla, Marruecos, Argelia, Túnez, Egipto), y llega a Palestina e Israel, en Oriente Próximo.

Osmia (Pyrosmia) gallarum Spinola, 1808

Osmia gallarum Spinola, 1808. Ins. Ligur., 2: 69

Osmia ruborum Dufour \& Perris, 1840. Ann. Soc. entomol. France, 9: 13

Osmia lapidistructor Ferton, 1921. Ann. Soc. entomol. France, 89: 343

Especie paleártica suroccidental, repartida por Europa central y el área mediterránea, en cuyo sector norte va 
desde la Península Ibérica hasta Turquía e Israel y, en el África septentrional, aparece en Marruecos y Argelia.

Warncke (1992b), a diferencia de van der Zanden (1984), que la establecía, consideraba a Osmia lapidistructor con categoría de subespecie, al igual que reconocía una tercera para la población mediterránea oriental.

Osmia (Pyrosmia) gemmea Pérez, 1896

Osmia purpurea Pérez, 1895. Esp. nouv. Mellif. Barbarie: 11 (non Cresson, 1864)

Osmia gemmea Pérez, 1896. Corr. Esp. nouv. Mellif. Barbarie: no paginada

Osmia ligulicornis Friese, 1899. Ent. Nachr., 25: 330

Descrita de "Barbarie", esta especie se ha registrado posteriormente desde Túnez, en el norte de África, hasta Oriente Próximo (Siria e Israel).

\section{Osmia (Pyrosmia) lobata Friese, 1899}

Osmia lobata Friese, 1899. Ent. Nachr., 25: 63

Osmia leucopyga Ducke, 1900. Ber. naturw-med. Ver. Innsbruck, 25: 223

Especie íbero-magrebí, repartida por Marruecos, Argelia y Túnez y la Península Ibérica.

Para van der Zanden (1991), Osmia leucopyga es una especie válida, independiente de Osmia lobata, que este autor localiza sólo en Argelia.

Osmia (Pyrosmia) nana Morawitz, 1874

Osmia nana Morawitz, 1874. Horae Soc. entomol. Ross., 10 (1873-1874): 152

Osmia tetradonta Benoist, 1934. Bull. Soc. entomol. France, 39: 106

Especie mediterránea oriental y transcaucásica. Se conoce desde Italia, por el Mediterráneo septentrional, hasta Siria y Líbano en Oriente Próximo, Argelia en el norte de África, y la Transcaucasia, en Asia Central.

Osmia (Pyrosmia) punica Pérez, 1895

Osmia punica Pérez, 1895. Esp. nouv. Mellif. Barbarie: 11

Descrita de "Barbarie", se reparte por el norte de África desde Marruecos y Argelia hasta Egipto.

Osmia (Pyrosmia) punica irherma Warncke, 1992

Osmia punica irherma Warncke, 1992. Linzer biol. Beitr., 24 (2): 905

Subespecie endémica de Marruecos.

Osmia (Pyrosmia) punica punica Pérez, 1895

Osmia punica Pérez, 1895. Esp. nouv. Mellif. Barbarie: 11

Subespecie del norte de África, desde Marruecos y Argelia hasta Egipto.

Osmia (Pyrosmia) saxicola Ducke, 1899

Osmia saxicola Ducke, 1899. Ent. Nachr., 25: 215
Osmia caelestina Benoist, 1934. Bull. Soc. entomol. France, 39: 160

Osmia cypricola Mavromoustakis, 1937. Ann. Mag. Nat. Hist., 20 (10): 520

Osmia posti Mavromoustakis, 1956. Ann. Mag. Nat. Hist., 9 (12): 856

Especie distribuida en el territorio mediterráneo, en España, Italia, Chipre y Turquía, en Líbano e Israel, en Oriente Próximo y en Tayikistán, en Asia Central.

Osmia (Pyrosmia) submicans Morawitz, 1870

Osmia submicans Morawitz, 1870. Horae Soc. entomol. Ross., 7: 314

Osmia giraudi Schmiedeknecht, 1885. Apidae Europaeae., 2 (12): 983

Especie paleártica occidental, que se distribuye, en Europa, hasta Rusia por el norte y Hungría, Grecia y Chipre, por el este, además de en el norte de África y Oriente Próximo. Por el sur llega hasta las Islas Canarias, donde hay otras tres subespecies.

Osmia (Pyrosmia) submicans hebraea Benoist, 1934

Osmia hebraea Benoist, 1934. Bull. Soc. entomol. France, 39: 160 Osmia aurantiaca Stanek, 1969. Annln. naturh. Mus. Wien, 73: 379

Subespecie que en el ámbito mediterráneo aparece en Sicilia, Chipre, Marruecos, Túnez y Egipto, además de en Israel y Jordania, en Oriente Próximo.

Osmia (Pyrosmia) submicans submicans Morawitz, 1870 Osmia submicans Morawitz, 1870. Horae Soc. entomol. Ross., 7: 314

Subespecie repartida en Europa hasta Rusia en el norte y hasta Hungría, Grecia y Croacia, por el este; en el sur llega hasta la Península Ibérica y Baleares.

Osmia (Pyrosmia) versicolor Latreille, 1811

Osmia versicolor Latreille, 1811. Encycl. méthod. Ins., 8: 586

Especie repartida por Europa central y meridional, el área mediterránea, Asia Menor y el Cáucaso.

Osmia (Pyrosmia) versicolor corrusca Erichson, 1835

Osmia corrusca Erichson, 1835. En: Waltl, Reise d'Tyrol, 2: 107 Megachile laeta Gistel, 1857. Vacuna, 2: 564

Megachile algarbiensis Strand, 1917. Archiv.f. Naturg., 82A (5): 98 (non Smith, 1853) (nomen novum para Osmia laeta Gistel, 1857)

Descrita del sur de Europa, esta subespecie se distribuye por Córcega, Sicilia, España peninsular, Baleares y Portugal, y Marruecos y Argelia, en el norte de África.

Tkalcu (1974b) y Schwarz et al. (1996) incluían a Osmia corrusca como sinónima de Osmia versicolor. El estatus subespecífico lo estableció van der Zanden (1984) y es mantenido así también por van der Zanden (1991), Warncke, (1992b) o Rasmont et al. (1995). 
Osmia (Pyrosmia) versicolor versicolor Latreille, 1811 Osmia versicolor Latreille, 1811. Encycl. méthod. Ins., 8: 586

Se distribuye por Europa central y meridional -incluida una única cita de España (van der Zanden, 1991; también referida por Warncke, 1992b)-, el territorio circunmediterráneo, Asia Menor y el Cáucaso.

Osmia (Pyrosmia) viridana Morawitz, 1874

Osmia viridana Morawitz, 1874. Horae Soc. entomol. Ross., 10 (1873-1874): 150

Especie distribuida en Europa central y meridional, en el área mediterránea desde España a Israel, en Próximo Oriente, Argelia y Túnez en el norte de África, el Cáucaso y Asia Central.

Osmia (Pyrosmia) viridana mulleolus van der Zanden, 1984

Osmia viridana mulleolus van der Zanden, 1984. Reichenbachia, 22 (24): 184

Subespecie distribuida por el sur de Europa, desde Bulgaria y hasta Suiza, por Francia, Italia, Grecia, así como en Turquía.

Osmia (Pyrosmia) viridana viridana Morawitz, 1874

Osmia viridana Morawitz, 1874. Horae Soc. entomol. Ross., 10 (1873-1874): 150

Osmia angulata Pérez, 1895. Esp. nouv. Mellif. Barbarie: 11

Osmia nicosiana Mavromoustakis, 1939. Ann. Mag. Nat. Hist., 4 (11): 155

Osmia rufispina Morawitz, 1875. En: Fedtschenko, Izv. Imp.

Obshch. Ljubit. Estest. Antrop. Etnog., 19: 83

Subespecie distribuida por Europa central y meridional, por el área mediterránea, el Próximo Oriente, Argelia y Túnez en el norte de África, el Cáucaso y Asia Central. Van der Zanden (1984a) daba una cita de España, que luego ya no incluía (van der Zanden, 1991).

Para Warncke (1992b), Osmia nicosiana es una subespecie diferenciada de Chipre.

Osmia (Pyrosmia) zarzisa Warncke, 1992

Osmia zarzisa Warncke, 1992. Linzer biol. Beitr., 24 (2): 913

Especie endémica de Túnez.

Subgénero Tergosmia Warncke, 1988

Osmia (Tergosmia) Warncke, 1988. Entomofauna, 9: 390 ESPECIE TIPO: Osmia tergestensis Ducke, 1897, por designación original

Distribución por el area mediterránea, Alemania, Polonia y Uzbekistán y Turkmekistán; Michener (2000) le asignaba 6 especies.

Osmia (Tergosmia) lunata Benoist, 1928

Osmia lunata Benoist, 1928. Bull. Soc. Scienc. Nat. Maroc, 8: 213
Especie conocida sólo de Francia, España y Marruecos. Para van der Zanden $(1985,1988 a)$ pertenecía al género Anthocopa en su subgénero nominal.

\section{Osmia (Tergosmia) tergestensis Ducke, 1897}

Osmia tergestensis Ducke, 1897. Ent. Nachr., 23: 41

Osmia ononidis Ferton, 1897. Act. Soc. Linn. Bordeaux, 52: 44 Osmia rondoui Pérez, 1902. Proc. ver. Soc. Linn. Bordeaux, 57: 66

Osmia wolhynica Noskiewicz, 1922. Polski. Pismo. Entomol., $1: 9$ Osmia atlantica Benoist, 1934. Bull. Soc. entomol. France, 39: 107

Especie distribuida en el área mediterránea, desde España hasta Turquía, en Europa meridional, y Marruecos en África, y en Europa central, hasta Polonia en el norte y hasta la Península de Crimea por el este.

Warncke (1988b) separaba de la subespecie nominal a Osmia tergestensis ononidis Ferton, 1897 (de España, Marruecos, Francia y Egipto) e incluía entre sus sinónimas a Osmia tergestensis remota Tkalcu, 1979 de Turquía. Van der Zanden (1988a) la consideraba un subgénero incierto de Anthocopa. Standfuss et al. (2003) incluyen esta especie como perteneciente al género Hoplitis.

\section{Género Protosmia Ducke, 1900}

Osmia (Protosmia) Ducke, 1900. Ber. naturw-med. Ver. Innsbruck, 25: 12

ESPECIE TIPO: Heriades glutinosus Giraud, 1871, por designación de Sandhouse, 1943

Anthocopa (Rhodosmia) Michener, 1943. Ann. Entomol. Soc. Am., 36: 85

ESPECIE TIPO: Osmia paradoxa Friese, 1899, por designación original

Distribución disjunta: área mediterránea y hasta el norte de la India y Birmania, y una especie en Norteamérica.

Subgénero Chelostomopsis Cockerell, 1925

Chelostomopsis Cockerell, 1925. Proc. California Acad. Sci., ser. 4, 14: 204

ESPECIE TIPO: Chelynia rubifloris Cockerell, 1898, por designación original

Rhaphidostoma Cockerell, 1936. Pan-Pacific Entomol., 12: 133 ESPECIE TIPO: Rhaphidostoma ceanothi Cockerell, 1936 = Chelynia rubifloris Cockerell, 1898, por designación original

Distribución disjunta: area mediterránea, desde Marruecos hasta Líbano y Turquía, y Norteamérica occidental. Michener (2000) le asignaba cuatro especies y, de ellas, una americana.

Protosmia (Chelostomopsis) capitata (Schletterer, 1889) Chelostoma capitatum Schletterer, 1889. Zool. Jb. Abt. Syst., 4: 647 Chelostoma mystax Pérez, 1895. Esp. nouv. Mellif. Barbarie: 20 Eriades trilobatus Friese, 1897. Ent Nachr, 23: 194

Especie íbero-magrebí, conocida de España, Marruecos y Argelia. 
Subgénero Nanosmia Griswold, 1998

Protosmia (Nanosmia) Griswold, 1998, en Griswold \& Michener,1998. J. Kansas Entomol, Soc., 70 (1997): 241 ESPECIE TIPO: Protosmia asensioi Griswold \& Parker, 1987, por designación original

Distribución por el área mediterránea, sureste de Asia y Cachemira. Michener (2000) le asignaba 5 ó 6 especies.

Protosmia (Nanosmia) asensioi Griswold \& Parker, 1987 Protosmia asensioi Griswold \& Parker, 1987. Psyche, 94: 51

Especie endémica de España.

Protosmia (Nanosmia) decipiens (Benoist, 1935)

Heriades decipiens Benoist, 1935. Bull. Soc. entomol. France, 40: 278

Especie endémica de Marruecos.

Protosmia (Nanosmia) minutula (Pérez, 1896)

Osmia pumila Pérez, 1895. Esp. nouv. Mellif. Barbarie: 18 (no disponible)

Osmia minutula Pérez, 1896. Corr. Esp. nouv. Mellif. Barbarie: no paginada

Osmia cataniae Strand, 1921. Archiv. f. Naturg., 87A (3): 321

Descrita de "Barbarie", esta especie se distribuye por Marruecos, Argelia y Túnez en el norte de África, y por el sureste de Francia, Sicilia en Italia, Austria, Alemania y Suiza en Europa.

Protosmia minutula se considera como tal aquí de acuerdo con Griswold \& Parker (1987), aunque era considerada anteriormente como una especie de Heriades, del subgénero Micreriades (Mavromoustakis, 1958; Tkalcu, 1977; van der Zanden, 1986).

Protosmia (Nanosmia) monstrosa (Pérez, 1895)

Osmia monstrosa Pérez, 1895. Esp. nouv. Mellif. Barbarie: 18 Osmia mirabilis Friese, 1899. Ent. Nachr., 25: 330

Descrita de "Barbarie", se reparte por Argelia en el norte de África, Chipre y Oriente Próximo, por Israel, Líbano y Siria.

\section{Subgénero Protosmia Ducke, 1900}

Distribución en el área mediterránea desde España hasta Israel, norte de Bulgaria y a través de Asia Menor hasta la Transcaucasia; Michener (2000) le asignaba 19 especies.

Protosmia (Protosmia) exenterata (Pérez, 1894)

Osmia exenterata Pérez, 1894. En: Ferton, Act. Soc. Linn. Bordeaux, 47: 212, 213

Especie repartida por el norte de África, por Marruecos, Argelia y Túnez y Francia, en Europa meridional; existe una única antigua cita española, referenciada por Ceballos (1956), que es preciso confirmar.
Protosmia (Protosmia) glutinosa (Giraud, 1871)

Heriades glutinosus Giraud, 1871. Ann. Soc. entomol. France ( $5^{\text {a }}$ sér.), $1: 389$

Especie mediterránea, desde la Península Ibérica hasta Grecia y Chipre, en Europa, Argelia, en el norte de África y el Cáucaso, en Asia.

La no inclusión de Osmia tiflensis Morawitz, 1876 como sinónima de esta especie, según Mavromoustakis (1939) y otros autores, se hace de acuerdo con Standfuss et al (2003), que la consideran una especie válida -Protosmia tiflensis-de Grecia.

Protosmia (Protosmia) humeralis (Pérez, 1895)

Osmia humeralis Pérez, 1895. Esp. nouv. Mellif. Barbarie: 18

Descrita de "Barbarie", se distribuye por Argelia, en el norte de África, España en el sur de Europa, y Turquía.

Protosmia (Protosmia) stelidoides (Pérez, 1895)

Osmia stelidoides Pérez, 1895. Esp. nouv. Mellif. Barbarie:

Descrita de "Barbarie", se distribuye por Marruecos y Argelia.

Protosmia (Protosmia) stigmatica (Pérez, 1895)

Osmia stigmatica Pérez, 1895. Esp. nouv. Mellif. Barbarie: 17 (non Schenck, 1855)

Descrita de "Barbarie", esta especie presenta distribución mediterránea, en España, Francia, Grecia, en Europa meridional, Marruecos y Argelia en el norte de África y en Asia Menor.

\section{Género Stenosmia Michener, 1941}

Stenosmia Michener, 1941. Amer. Midland Natur., 26 (1): 165 ESPECIE TIPO: Osmia flavicornis Morawitz, $1877^{11}$, por designación original

Distribución por el área mediterránea, en España y Turquía, el norte de África y Asia Central. No se han descrito subgéneros y Michener (2000) le asignaba 11 especies.

Stenosmia albatera (Warncke, 1991)

Osmia albatera Warncke, 1991. Entomofauna, 12: 405

Especie endémica de España.

Stenosmia hartliebi (Friese, 1899)

Osmia hartliebi Friese, 1899. Ent. Nachr., 25: 333

Especie distribuida por el norte de África, en Argelia, Túnez, Libia y Egipto.

Véase la nota al pie en Osmia dentiventris Morawitz, 1877, en relación con el año de publicación de estas especies. 
Van der Zanden (1988a) consideraba esta especie como Anthocopa (Anthocopa) hartliebi (Friese, 1899); su situación en Stenosmia sigue a Warncke (1991b).

Stenosmia minutissima (Warncke, 1991)

Osmia minima Schulthess, 1924. Bull. Soc. Hist. Nat. Afrique $d u$ Nord, 15: 314 (no disponible)

Osmia minutissima Warncke, 1991. Entomofauna, 12: 404

Especie distribuida en Marruecos y Túnez.

Stenosmia tagmouta (Warncke, 1991)

Osmia tagmouta Warncke, 1991. Entomofauna, 12: 405

Especie endémica de Marruecos.

Género Wainia Tkalcu, 1980

Wainia Tkalcu, 1980. Annotationes Zoologicae et Botanicae 135: 1

ESPECIE TIPO: Wainia lonavlae Tkalcu, 1980, por designación original.

Wainia (Trichotosmia) Tkalcu, 1980. Annotationes Zoologicae et Botanicae 135: 16.

ESPECIE TIPO: Wainia consimilis Tkalcu, 1980, por designación original.

Wainia contiene 3 subgéneros de los que sólo el subgénero Caposmia Peters, 1984 aparece en el territorio considerado en este trabajo. El subgénero nominal se reparte desde Namibia y Suráfrica hasta Kenia y, por el este, hasta Yemen, Pakistán, India y las Filipinas. El subgénero Wainiella Griswold, 1998, está distribuido desde Suráfrica hasta Kenia (Michener, 2000).

\section{Subgénero Caposmia Peters, 1984}

Osmia (Caposmia) Peters, 1984. Entomofauna 5: 378. ESPECIE TIPO: Osmia braunsi Peters, 1984, por designación original.

Anthocopa (Eremoplosmia) van der Zanden, 1991. Reichenbachia 28: 164.

ESPECIE TIPO: Osmia eremoplana Mavromoustakis, 1949, por designación original

Distribuido en Israel, Norte de África y Suráfrica (van den Zanden, 1991; Michener, 2000).

Wainia (Caposmia) guichardi (van der Zanden, 1991)

Anthocopa (Eremoplosmia) guichardi van der Zanden, 1991. Reichenbachia, 28 (31): 164

Especie endémica de Marruecos.

\section{Incertae Sedis}

Heriades integra Benoist, 1934

Heriades integra Benoist, 1934 Bull. Soc. entomol. France, 39: 159
Descrita de Marruecos, sin corroborar con otros datos posteriores.

Heriades maroccana Benoist, 1928

Heriades maroccana Benoist, 1928. Bull. Soc. Sci. Nat. Maroc, 8: 212

Descrita de Marruecos, sin corroborar con otros datos posteriores.

Osmia luctuosa Lucas, 1849

Osmia luctuosa Lucas, 1849. Expl. Sci. ent., Algerie, 3: 205 Osmia cavigena Pérez, 1895. Esp. nouv. Mellif. Barbarie: 19

Descrita de Argelia, citada luego de "Barbarie" (Pérez, 1895) y de nuevo de Argelia (Ducke, 1900).

Osmia octomaculata Pérez, 1895

Osmia octomaculata Pérez, 1895. Esp. nouv. Mellif. Barbarie: 17

Descrita de "Barbarie" y citada de Argelia (Ducke, 1900), es considerada también de posición incierta por van der Zanden (1988a).

Especies del área mediterránea occidental del subgénero Stenoheriades Tkalcu, 1984

Pseudoheriades (Stenoheriades) Tkalcu, 1984. Annot. Zool. Bot., 158: 1

ESPECIE TIPO: Pseudoheriades hofferi (Tkalcu, 1984), por designación original

Se trata de un subgénero del género Pseudoheriades Peters 1970, establecido por Tkalcu (1984) en el que, además de la especie tipo, de Bulgaria -más tarde citada en Turquía por van der Zanden (1994b)-, incluía otras dos especies: Pseudoheriades coelostoma (Benoist, 1935) de Asia Menor y Pseudoheriades asiaticus (Friese, 1921) repartida desde Grecia y Bulgaria hasta Asia Menor (van der Zanden, 1994b).

De acuerdo con Michener (2000), el subgénero Stenoheriades (que él eleva a rango genérico) contiene alrededor de 15 especies y su distribución es paleártica occidental y etiópica, desde el área mediterránea, incluida Bulgaria en el norte y Marruecos y España, hasta el sureste de Asia, Suráfrica y Madagascar. No obstante, por el momento, no se han podido localizar las especies o referencias de las citas concretas de Marruecos y España u otras que justificarían su inclusión en el área mediterránea occidental.

\section{Comentario final y conclusiones}

La naturaleza de un trabajo como éste hace difícil extraer conclusiones distintas del propio contenido global del catálogo en sí mismo, pero a modo 
Tabla 1.- Distribución geográfica de los géneros de Osmiini.

Table 1.- Geographical distribution of the genera of Osmiini.

\begin{tabular}{lc}
\hline GÉNERO & DISTRIBUCIÓN GEOGRÁFICA \\
\hline Chelostoma & Holártica \\
Haetosmia & Paleártica y Etiópica \\
Heriades & Subcosmopolita \\
Hofferia & Paleártica \\
Hoplitis & Holártica \\
Hoplosmia & Paleártica \\
Osmia & Holártica \\
Protosmia & Holártica \\
Stenosmia & Paleártica \\
Wainia & Paleártica y Etiópica \\
\hline
\end{tabular}

de resumen puede establecerse que se han rastreado, revisado y consignado todos los taxones de Osmiini del territorio comprendido en el área mediterránea occidental, hasta el nivel de subespecie, sus sinonimias y citas, desde cada descripción original -salvo muy raras excepciones- hasta las más recientes. El total es de 10 géneros, 33 subgéneros, 243 especies y 278 subespecies.

En relación con su distribución geográfica (Tabla 1), aunque existe alguna especie subcosmopolita, el patrón corológico por especies (Tabla 2) muestra un mayor porcentaje del conjunto de los mediterráneos $(25 \%)$, seguido por los corotipos norafricanos $(22 \%)$ y paleárticos $(21 \%)$ y en menor proporción, el europeo (8\%), íbero-magrebí $(4 \%)$, holártico $(2 \%)$ y los endemismos ibéricos $(1 \%)$. El heterogéneo conjunto que convencionalmente reúne los endemismos no ibéricos da un total del $17 \%$.

De cualquier modo, los estudios taxonómicos en curso sobre los integrantes de la familia en el territorio estudiado permitirán en el futuro hacer afirmaciones biogeográficas más concluyentes.

\section{AGRADECIMIENTOS}

A Mr. Le Goff por poner a nuestra diposición una amplia información sobre megaquílidos de España, al Dr. Alonso Zarazaga por resolvernos algunas cuestiones nomenclaturales y a Pepe Fernández por facilitarnos y aclarar ciertas pesquisas bibliográficas.
Tabla 2.- Principales corotipos que existen en la tribu Osmiini.

Table 2.- Main chorotypes in the tribe Osmiini.

\begin{tabular}{lc}
\hline PATRÓN COROLÓGICO & $\mathbf{\%}$ \\
\hline Holártica & 2 \\
Paleártica & 1 \\
Paleártica occidental & 20 \\
Europea & 8 \\
Circunmediterránea & 12 \\
Mediterránea occidental & 13 \\
Mediterráneo-turánica & 0 \\
Norte de África & 22 \\
Íbero-magrebí & 4 \\
Endemismos ibéricos & 1 \\
Endemismos no ibéricos & 17 \\
\hline
\end{tabular}

\section{Referencias}

AlfKen, J. D., 1914. Beiträge zur Kenntnis der Bienenfauna von Algerien. Memoires de la Société Entomologique de Belgique, 22 [1913-1914]: 185-237.

Alfken, J. D., 1927. Apiden (Ins. Hym.) aus dem nördlichen und östlichen Spanien. Senckenbergiana biologica, 9(6): 223-234.

AlfKEN, J. D., 1941. Welchen wissenschaftlichen namen hat die schwarze Mörtelbiene zu führen? (Hym. Apid.). Mitteilungen der Münchener Entomologischen Gesellschaft, 31: 89-92.

BAKER, D. B., 1996. Hymenoptera collections of Boyer de Fonscolombe: Apoidea in the University Museum, Oxford. Journal of Natural History, 30: $537-550$

BANASZAK, J., 2000. A checklist of the bee species (Hymenoptera, Apoidea) of Poland, with remarks on their taxonomy and zoogeography: revised version. Fragmenta Faunistica, 43 (14): 135-193.

BanAsZaK, J. \& RomasenKo, L., 2001. Megachilid bees of Europe (Hymenoptera, Apoidea, Megachilidae). Pedagogical University of Bydgoszcz. Bydgoszcz. $239 \mathrm{pp}$.

BENOIST, R., 1924. Sur la provenance de quelques Hyménoptères Mellifères décrits par J. Pérez. Bulletin de la Société entomologique de France, 29: 109-111.

BENOIST, R., 1926. Hyménoptères mellifères des environs de Paris. Annales de la Société entomologique de France, 95: 210. 
Benoist, R., 1927. Hyménoptères Mellifères nouveaux du Maroc. Bulletin de la Société des Sciences Narturelles du Maroc, 7 : 169-174.

BenOIST, R., 1928a. Notes diverses sur les Hyménoptères Mellifères Bulletin de la Société entomologique de France, 33: 107-109.

BenOIST, R., 1928b. Hyménoptères Mellifères nouveaux du Maroc (Diagnoses préliminaires). Bulletin de la Société des Sciences Naturelles du Maroc, 8: 212-215.

BEnOIST, R., 1931a. Les Osmies de la fauna française (Hymenopt. Apidae). Annales de la Société entomologique de France, 100: 23-60.

Benoist, R., 1931b. Descriptions de nouvelles espèces africaines du genre Heriades (Hym. Apidae). Annales de la Société entomologique de France, 100: 99-105.

BenOIST, R., 1934a. Descriptions d'espèces nouvelles de Hyménoptères Mellifères. Bulletin de la Société entomologique de France, 39: 106-110.

BenOIST, R., 1934b. Descriptions d'espèces nouvelles de Hyménoptères Mellifères. Bulletin de la Société entomologique de France, 39: 158-160.

Benoist, R., 1943. Contribution à la connaissance de la faune des Hyménoptères de l'Afrique du Nord française. Bulletin de la Société entomologique de France, 48: 41-44, 87-88.

BENOIST, R., 1950. Hyménoptères récoltés par une mission suisse au Maroc (1947). Bulletin de la Société des Sciences Naturelles du Maroc, 30: 183-193.

BENOIST, R., 1969. Contribution à la connaissance de la faune des Apides de 1'Afrique du Nord et de 1'Arabie (Hym). Bulletin de la Société entomologique de France, 74: 243-247.

BERLAND, L., 1943. Récoltes entomologiques faites par L. Berland a Villa-Cisneros (Río de Oro). Hyménoptères. Bulletin du Museum d'Histoire Naturelle de Paris, $2^{\mathrm{e}}$ série, 15(5): 311-317.

Bofill, J. M., 1905. Catàlech de Insectes de Catalunya. Hymenòpters. Butlletí de la Institució Catalana d' Historia Natural, $\mathrm{n}^{\circ}$ 7: 41-47, $\mathrm{n}^{\circ}$ 8: 48-53.

Buysson, R. DU, 1899. Sur quelques osmies de Tunisie. Annales de la Société entomologique de France, 68: 666-668.

Ceballos, G., 1956. Catálogo de los himenópteros de España. Trabajos del Instituto Español de Entomología. (C.S.I.C.). Madrid. 554 pp.

CombA, L. \& ComBA, M., 1991. Catalogo degli Laziali (Hymenoptera, Apoidea). Fragmenta Entomologica, 22, suppl.: 1-169.

Comba, M. \& CombA, L., 2001. Gli Apoidei (Hymenoptera: Aculeata) alpini: diversità e abbondanza in alcune fasce altitudinali delle Valli del Pellice, Angrogna e Germanasca (Alpi Cozie). Bolletino del Museo regionale di Scienze Naturali di Torino, 18(1): 11-97.
Diniz, A., 1960. Notas sobre himenópteros de Portugal, I. Memórias e Estudos do Museu Zoológico da Universidade de Coimbra, 266: 1-37.

Dours, A., 1873. Hyménoptères du Bassin Méditerranéen. Andrena (suite). Biareolina, Eucera. Revue et Magasin de Zoologie, 1(3): 274-325.

Dubitzky, A., Blank, S. M. \& SchÖnitzer, K., 2005. Die Hymenopterenfauna (Symphyta, Aculeata) im Norden von Dachau, Bayern. Linzer Biologische Beiträge, 37(1): 235-314.

Ducke, A., 1900. Die Bienengattung Osmia Panz. Berichte des Naturwissenschaftlich-Medizinischen Vereins in Innsbruck, 25 [1899-1900]: 1-323.

Dufour, L., 1849. Sur quelques hyménoptères nouveaux ou peu connues de l'Espagne. Annales des Sciences Naturelles, sér. 3, 11: 91-98.

Dufour, L., 1853. Signalements de quelques espèces nouvelles ou peu connues d'hyménoptères Algeriens. Annales des Sciences Naturelles, sér. 3, 1: 375-382.

Dusmet, J. M., 1920. Observaciones sobre la procedencia española de muchos ápidos descritos por Pérez en "Especes nouvelles de Melliferes de Barbarie". Boletín de la Real Sociedad española de Historia Natural, 20: 168-169.

Dusmet, J. M., 1921. Contribución al conocimiento de los himenópteros de Portugal. Lista de los cazados en junio de 1921. Asociación española para el Progreso de las Ciencias. Congreso de Oporto (1921) 6 (Ciencias Naturales): 183-191.

EBMer, A. W., 2001. Hymenopterologische Notizen aus Österreich -14. Linzer Biologische Beiträge, 33(1): 435-460.

EBmer, A. W., 2003. Hymenopterologische Notizen aus Österreich -16. Linzer Biologische Beiträge, 35(1): 313-403.

EBmer, A. W., 2005. Hymenopterologische Notizen aus Österreich -18. Linzer Biologische Beiträge, 37(1): 321-342.

ERlANDSSON, S., 1991. Hymenoptera Aculeata from the European parts of the Mediterranean countries. IV. Bolletino del Museo civico di Venezia, 40 [1989]: 89-95.

FERTON, C., 1890. Recherches sur les moeurs de quelques espèces Algériennes d'hyménoptères du genre Osmia. Actes de la Société Linnéenne de Bordeaux, 44: 201-209.

FrIESE, H., 1898. Die Bienen Europa's (Apidae europaeae) Theil IV. Solitäre Apiden. Genus Eriades, Genus Trachusa, Genus Anthidium. C. Lampe. Innsbruck. $303 \mathrm{pp}$.

Friese, H., 1899a. Neue Arten der Bienengattung Osmia. (Palaearktisches Gebiet). Entomologische Nachrichten, 25(2): 25-27.

FrIESE, H., 1899b. Neue Arten der Bienengattung Osmia. (Palaearktisches Gebiet). II. Entomologische Nachrichten, 25 (4): 61-64. 
FrIESE, H., 1899c. Neue palaearktische Sammelbienen. Entomologische Nachrichten, 25 (21-22): 321-346.

Friese, H., 1921. Neue Arten der Bauchsammler (Hym). Deutsche Entomologische Zeitschrift 1920: 49-55.

Gayubo, S. F., Torres, F. \& Heras, C., 1990. Estudio sobre las abejas de la Sierra de Gredos (Hymenoptera, Apoidea). Cuadernos Abulenses, 11: 83-166.

GonzÁlez, J. A., Gayubo, S. F. \& Torres, F., 2002. Diversidad, conservación e importancia en la gestión de los himenópteros megaquílidos (Insecta, Hymenoptera, Megachilidae) como agentes polinizadores en el espacio natural de Arribes del Duero. Gestión y conservación de la fauna silvestre euromediterránea. Estudios y proyectos. Universidad de León - Universitá degli Studi di Napoli "Federico II" - Universidades de Tras-osMontes e Alto Douro - WAVES. León (España): 55-77.

Griswold, T. L. \& MichenER, C. D., 1998. The classification of the Osmiini of the Eastern Hemisphere (Hymenoptera, Megachilidae). Journal of the Kansas Entomological Society, 70(3) [1997]: 207-253.

Griswold, T. L. \& PArker, F. D., 1987. A new species of Protosmia Ducke from Spain with notes on related species (Hymenoptera, Megachilidae). Psyche, 94: 51-56.

HAEseler, V., 2005. Osmia chrysolepta sp. nov a new bee of the subgenus Hemiosmia Tkalcu, 1975 with notes on the identification and distribution of species closely related to $O$. (Hemiosmia) balearica Schmiedeknecht, 1885 (Hymenoptera, Apoidea, Megachilidae. Entomofauna, 26 (27): 473-492.

Kerzhner, J. M., 1984. Dates of publications of "Trudy Russkogo Entomologischeskogo Obshchestva" and "Horae Societatis Entomologicae Rossicae", 18611932. Revue d'Entomologie de l'URSS, 63 (4): 1984.

LE Goff, G., 2003. Une nouvelle espèce ibérique du genre Hoplitis Klug (Hymenoptera, Apoidea, Megachilidae). Bulletin de la Société entomologique de France, 108 (1) : 67-70.

Latreille, P. A., 1811. Encyclopédie méthodique Histoire naturelle. Insectes (Osmia). Encyclopédie méthodique Insectes, 8: 567-587.

LuCAS, H., 1849. Exploration scientifique de l'Algérie pendant les années 1840, 1841, 1842. Hyménoptères. Exploration scientifique entomologique de l'Algerie, 3: $141-344$.

MAIDL, F., 1922. Beiträge zur Hymenopterenfauna Dalmatiens, Montenegros und Albaniens. Annalen des Naturhistorischen Museums in Wien, 35: 36-106.

Mavromoustakis, G. A., 1939. On the bees of the genera Osmia and Megachile from Cyprus (Apoidea). I. The Annals and Magazine of Natural History, (11), 4: 154-160.

Mavromoustakis, G. A., 1947. On some Megachilidae from Spain and Morocco (Hym., Apoidea). Eos, 23: 357-367.
Mavromoustakis, G. A., 1948. On the bees (Hymenoptera, Apoidea) of Cyprus. Part I. The Annals and Magazine of Natural History, (12), 1: 541-587.

Mavromoustakis, G. A., 1958. The bees (Hymenoptera, Apoidea) of Attica (Greece). Part I. The Annals and Magazine of Natural History, (13), 1: 433-447.

Mavromoustakis, G. A., 1960. A contribution to our knowledge of the bees (Hymenoptera, Apoidea) of the Island of Rhodos (Greece). Part I. The Annals and Magazine of Natural History, 2(13): 281-302.

Michener, C. D., 1997. Genus-group names of bees and supplemental family-group names. Scientific Papers, Natural History Museum. The University of Kansas, 1: $1-81$.

Michener, C. D., 2000. The bees of the world. The Johns Hopkins University Press. Baltimore and London. viii + 913 pp.

Morawitz, F., 1879. Nachtrag zur Bienenfauna Caucasiens. Horae Societatis entomologicae Rossicae, 14 [1877-1878-1879]: 3-112.

Morawitz, F., 1886. Neue transcaucasische Apidae. Horae Societatis entomologicae Rossicae, 20 [18851887]: 57-81.

Morawitz, F., 1887. Insecta in itinere cl. N. Przewalskii in Asia Centrali novissime lecta. I. Apidae. Horae Societatis entomologicae Rossicae, 20 [1885-1887]: 195-229.

Morice, F. D., 1916. List of some Hymenoptera from Algeria and the M'zazb country. Novitates Zoologicae, 23: 241-246.

NADIG, A. von, 1933. Beitrag zur Kenntnis der Hymeopterenfauna von Marokko und Westalgerien. Erster Teil: Apidae, Sphegidae, Vespidae. Jaresbericht der Naturforschenden Gesellschaft Graubundens, 71 [1932-1933]: 38-107.

Nobile, V. \& Tomarchio, S., 2000. Apoidei nuovi o poco noti di alcune regione d'Italia (Hymenoptera, Apoidea, Megachilidae). I. Bolletino della Accademia Gioenia di Scienze Naturali, 33(358): 43-54.

OrNosA, C., 2001. Anotaciones relativas a ciertas publicaciones antiguas sobre apoideos Hymenoptera, Apoidea). Boletín de la Asociación española de Entomología, 25(3-4): 17-30.

Ornosa, C. \& OrTIZ-SÁnchez, F. J., 2004. Hymenoptera, Apoidea I. En: Fauna Ibérica, vol. 23. Ramos, M.A. et al., (eds.). Museo Nacional de Ciencias Naturales. CSIC. Madrid. 556 pp.

OrTIZ-SÁNCHEZ, F. J., 1990. Contribución al conocimiento de las abejas del género Anthidium Fabricius, 1804 en Andalucía (Hym., Apoidea, Megachilidae). Boletín de la Asociación española de Entomología, 14: 251-260.

Pagliano, G., 1994. Catalogo degli imenotteri italiani. IV. (Apoidea: Colletidae, Andrenidae, Megachilidae, Anthophoridae). Memoires della Società entomologica italiana, Genova, 72 [1993]: 331-467. 
PÉREZ, J., 1879. Contribution à la fauna des Apiaires de France. Actes de la Société Linnéenne de Bordeaux, 33: 119-229.

PÉrez, J., 1890. Catalogue des Mellifères du SudOuest. Actes de la Société Linnéenne de Bordeaux, 44: 133-200.

PÉREZ, J., 1895. Espèces nouvelles de Mellifères de Barbarie (Diagnoses préliminaires). Gounouilhou. Bordeaux. 64 pp.

PÉREZ, J., 1905. Espéces nouvelles de Hymenoptéres de Catalogne. Butlletí de la Institució Catalana $d^{\prime}$ Historia Natural, $\mathrm{n}^{\circ}$ 6: 81-88.

Pérez-ÍñIgo, C., 1980. Nota sobre los ápidos (Hym., Apoidea) de los Montes Universales, Sierras de Cuenca y Albarracín (provincias de Cuenca y Teruel). Boletín de la Asociación española de Entomología, 4: 43-49.

PÉrez-ÍÑigo, C., 1984. Los Ápidos de la Sierra de Guadarrama II. Fam. Andrenidae y Megachilidae (Hym., Apoidea). Graellsia, 39 [1983]: 103-126.

Peters, D. S., 1978. Systematik und Zoogeographie der west-paläarktischen Arten von Osmia Panzer, 1806 s. st., Monosmia Tkalcu, 1974 und Orientosmia n. subgen. (Insecta: Hymenoptera, Megachilidae). Senckenbergiana biologica, [1977], 58(5/6): 287- 346.

Quaranta, M., Ambroselli, S., Barro, P., Bella, S., Carini, A., Celli, G., Cogoi, P., Comba, L., Comoli, R., Felicioli, A., Floris, I., Intoppa, F., Longo, S., Maini, S., Manino, A., Mazzeo, G., Medrzycki, P., Nardi, E., Niccolini, L., Palmieri, N., Patetta, A., Piatti, C., Piazza, M. G., Pinzauti, M., Porporato, M., Porrini, C., Ricciardelli D'Albore, G., Romagnoli, F., Ruiu, L., SATta, A. \& Zandigiacomo, P., 2004. Wild bees in agroecosystems and semi-natural landscapes. 1997-2000 collection period in Italy. Bulletin of Insectology, 57(1): 11-61.

Rasmont, P., Ebmer, A., Banaszak, J. \& Zanden, G. VAN DER, 1995. Hymenoptera Apoidea Gallica. Bulletin de la Société entomologique de France, 100(hors série): 1-98.

Rust, R. W., 1974. The Systematics and Biology of the Genus Osmia, Subgenera Osmia, Chalcosmia, and Cephalosmia (Hymenoptera: Megachilidae). The Wasmann Journal of Biology, 32(1): 1-93.

SAunders, E., 1881. Notes on the entomology of Portugal. VI. Hymenoptera Aculeata. Entomologist's Monthly Magazine, 18: 165-171.

SAUNDERS, E., 1904. Hymenoptera Aculeata from Majorca (1901) and Spain (1901-2) with introduction, notes and Appendix by prof. Edward B. Poulton, F.R.S. Transactions of the Entomological Society of London, 1904: 591-665.

SAUNDERS, E., 1908. Hymenoptera Aculeata collected in Algeria by the Rev. A.E. Eaton, M.A., F.E.S. and the Rev. Francis David Morice, M.A., F.E.S. Part. III.
Anthophila. Transactions of the Entomological Society of London, 2: 177-274.

SCHUlthess, A., 1924. Contribution à la connaissance de la faune des Hyménoptères de l'Afrique du Nord. Bulletin de la Société d' Histoire Naturelle de l'Afrique du Nord, 15: 293-320.

SchwArZ, M. \& GuSENLEITNER, F., 1999. Weitere Angaben zur Bienenfauna Österreichs Vorstudie zu einer Gesamtbearbeitung der Bienen Österreichs II (Hymenoptera, Apidae). Entomofauna, 20(11): 185256.

Schwarz, F., Gusenleitner, P., Westrich, P. \& Dathe, H. H., 1996. Katalog der Bienen Österreichs, Deutschland und der Schweiz (Hymenoptera, Apidae). Entomofauna, supplementum 8: 1-398.

SPINOLA, M., 1843. Notes sur quelques Hyménoptères peu connus, recueillis en Espagne, pendant l'année 1842, par M. Victor Ghiliani, voyager-naturaliste. Annales de la Société entomologique de France, sér. 2, 1: 111-144.

Standfuss, K., Standfuss, L. \& Schwarz, M., 2003. Zur aktuellen Bienenfauna der Ölbaumzone in SOThessalien/Griechenland (Hymenoptera: Apoidea: Apiformes). 1. Megachilidae. Entomofauna, 24 (20): 293-304.

StANEK, E., 1964. Beitrag zur Kenntnis der Solitärbienen der Gattung Osmia Panz. des westlichen Mediterraneums. Bolletino dell'Istituto di Entomologia della Università degli Studi di Bologna, 27: 193-214.

SuÁrez, F. J. \& MARTínez, J., 1972. Apidos de la provincia de Almería. $1^{\text {a }}$ Nota. (Hymenoptera, Apoidea). Archivos del Instituto de Aclimatación, C.S.I.C., 17: 5-20.

TKAlcu, B., 1966. Metallinella gen. n. der Familie Megachilidae (Hymenoptera, Apoidea). Acta entomologica bohemoslovaca, 63: 200-202.

TKAlcu, B., 1969. Beiträge zur Kenntnis der Fauna Afghanistans. Osmiini, Megachilidae, Apoidea, Hym. Acta Musei Moraviae, 54: 324-346.

TKALCU, B., 1974a. Revision und Klassification der bisher zur Untergattung Hoplosmia Thomson gestellen Anthocopa-Arten (Hymenoptera, Apoidea, Megachilidae). Acta entomologica bohemoslovaca, 71: 114-135.

TKALCU, B., 1974b. Ergebnisse der Albanien Expedition 1961 des "Deutschen Entomologischen Institutes" (Hymenoptera, Apoidea, Megachilidae). Beiträge zur Entomologie, Berlin, 24(5-8): 323-348.

TKAlcu, B., 1975a. Revision der europäischen Osmia (Chalcosmia)-Arten der fulviventris-Gruppe (Hymenoptera: Apoidea: Megachilidae). Vestník Ceskoslovenské Spolecnosti Zoologické, 39(4): 297-317.

TKALCU, B., 1975b. Sammelergebnisse der von RNDr. A. Hoffer geleiteten Algerien-Expeditionen in den 
Jahren 1971 und 1972 (Hymenoptera: Apoidea). 1. Teil: Megachilidae. Acta Rerum Naturalium Musei Nationalis Slovaci, Bratislava, 21: 165-190.

TKAlcu, B., 1977. Taxonomisches zu einigen paläarktischen Bienenarten (Hymenoptera: Apoidea). Vestnik Ceskoslovenské Spolecnosti Zoologické, 41(3): 223239.

Tkalcu, B., 1983. Die Europäischen Osmia Arten der Untergattung Melanosmia (Hymenoptera, Apoidea, Megachilidae). Vestník Ceskoslovenské Spolecnosti Zoologické, 47 (3): 140-159.

TKAlcu, B., 1984. Neue Paläarktische Arten der Gattungen Pseudoheriades und Archeriades mit der Beschreibung von Hofferia gen. n. (Hymenoptera, Apoidea, Megachilidae). Annotationes Zoologicae et Botanicae, 158: 1-22.

TKalcu, B., 2000. New palaearctic species of the genera Anthocopa and Hoplitis (Hymenoptera, Apoidea, Megachilidae). Acta Societatis zoologicae bohemicae, 64: 305-330.

VACHAL, J., 1891. Hyménoptérologie paléarctique. Revue d'Entomologie, 10: 63-67.

VACHAL, J., 1910. Espèces nouvelles d'Apides d'Espagne et du Maroc. Boletín de la Real Sociedad española de Historia Natural, 10: 176-180.

VERGÉs, F., 1964. Algunos ápidos capturados en el término de Canet de Mar (Barcelona). Graellsia, 20: 231-244.

Warncke, K., 1988a. Die Bienengattung Osmia Panzer, 1806, ihre Systematik in der Westpaläarktis und ihre Verbreitung in der Türkei. 1. Untergattung Helicosmia Thomson, 1872. (Hymenoptera, Apidae). Entomofauna, 9(1/1): 1-45.

WARNCKE, K., 1988b. Die Bienengattung Osmia Panzer, 1806, ihre Systematik in der Westpaläarktis und ihre Verbreitung in der Türkei. 2. und 3. Untergattungen Tergosmia und Exosmia. Entomofauna, 9(20): 389403.

WARnCKe, K., 1991a. Die Bienengattung Osmia Panzer, 1806, ihre Systematik in der Westpaläarktis und ihre Verbreitung in der Türkei. 5. Untergattung Pentadentosmia subg. nov. Entomofauna, 12(2): 13-28.

WARNCKE, K., 1991b. Die Bienengattung Osmia Panzer, 1806, ihre Systematik in der Westpaläarktis und ihre Verbreitung in der Türkei. 6. Untergattung Stenosmia Michener, 1941, comb. nov. (Hymenoptera, Apidae). Entomofauna, 12(24): 401-409.

WarnCKe, K., 1991c. Die Bienengattung Osmia Panzer, 1806, ihre Systematik in der Westpaläarktis und ihre Verbreitung in der Türkei. 7. Die Untergattung Foveosmia nov. Linzer Biologische Beiträge, 23(1): 267-281.

WARNCKE, K., 1991d. Die Bienengattung Osmia Panzer, 1806, ihre Systematik in der Westpaläarktis und ihre Verbreitung in der Türkei. 8. Die Untergattung
Cephalosmia Sladen, 1916. Linzer Biologische Beiträge, 23(1): 283-287.

WARNCKE, K., 1991e. Die Bienengattung Osmia Panzer, 1806, ihre Systematik in der Westpaläarktis und ihre Verbreitung in der Türkei. 9. Die Untergattung Annosmia subg. n. Linzer Biologische Beiträge, 23(1): 307-336.

WARnCKe, K., 1991f. Zur Synonymie in der Bienengattung Osmia Panzer, 1806 (Hym., Apidae). Linzer Biologische Beiträge, 23(2): 567-568.

Warncke, K., 1991g. Die Bienengattung Osmia Panzer, 1806, ihre Systematik in der Westpaläarktis und ihre Verbreitung in der Türkei. 10. Die Untergattung Alcidamea Cress. Linzer Biologische Beiträge, 23(2): 701-751.

WARNCKE, K., 1992a. Die westmediterranen Arten der Bienen Osmia subg. Hoplitis Klug, 1807. Linzer Biologische Beiträge, 24(1): 103-121.

WARnCKe, K., 1992b. Die Bienengattung Osmia Panzer, 1806, ihre Systematik in der Westpaläarktis und ihre Verbreitung in der Türkei. 11. Die Untergattung Pyrosmia Tkalcu, 1975. Linzer Biologische Beiträge, 24(2): 893-921.

Westrich, P., 1999. A review of the identity of Osmia cerinthidis Morawitz (Hymenoptera, Apidae) in Belgium. Linzer Biologische Beiträge, 31(2): 783.

ZANDEN, G. VAN DER, 1961. Hymenoptera aculeata van Andorra en de France Pyreneeën. Entomologische Berichten, 18: 89-91.

ZANDEN, G. VAN DER, 1983. Taxonomische und faunistische Bemerkungen $\mathrm{zu}$ einigen Paläarktischen Bauchsammler-Arten (Insecta, Hymenoptera, Apoidea, Megachilidae). Faunistische Abhandlungen Staatliches Museum für Tierkunde in Dresden, [1982], 10(3): 124-139.

ZANDEN, G. VAN DER, 1984. Beitrag zur BauchsammlerFauna von Spanien. Mitteilungen aus dem zoologischen Museum in Berlin, 60(2): 225-227.

ZANDEN, G. VAN DER, 1985. Ergebnisse der Untersuchungen der von R. BENOIST beschriebenen Osmia-Arten, mit Liste seiner Schriften (Hymenoptera, Apoidea, Megachilidae). Reichenbachia, 23(11): 47-72.

ZANDEN, G. VAN DER, 1986. Untersuchungen an einigen bekannte Osmia und Megachile Arten, mit Beschreibung zweier neuer Taxa. (Hymenoptera, Apoidea, Megachilidae). Reichenbachia, 24(7): 65-74.

ZANDEN, G. VAN DER, 1988a. Beitrag zur Systematik und Nomenklatur der paläarktischen Osmiini, mit Angaben über ihre Verbreitung. Zoologische Mededelingen, Leiden, 62(9): 113-133.

ZANDEN, G. VAN DER, 1988b. Nomenklatorische und taxonomische Bemerkungen zu einigen paläarktischen Arten der Familie Megachilidae. Reichenbachia, 26(10): 55-64. 
ZANDEN, G. VAN DER, 1989. Neue oder wenig bekannte Arten und Unterarten der paläarktischen Megachiliden (Insecta, Hymenoptera, Apoidea, Megachilinae). Entomologische Abhandlungen Staatliches Museum für Tierkunde in Dresden, 53(6): 71-86.

ZANDEN, G. VAN DER, 1990. Nomenklatorische Änderungen für einige paläarktische Arten der Familie Megachilidae (Insecta, Hymenoptera, Apoidea). Reichenbachia, 28(9): 51-54.

ZANDEN, G. VAN DER, 1991. Systematik und Verbreitung der paläarktischen Arten der Untergattung Caerulosmia Van der Zanden, 1989 (Hymenoptera, Apoidea, Megachilidae). Linzer Biologische Beiträge, 23(1): 37-78.

ZANDEN, G. VAN DER, 1992a. Neue oder unvollständig bekkante Arten paläarktischer Bauchsammler. (Hymenoptera Aculeata, Apoidea, Megachilidae). Linzer Biologische Beiträge, 24(1): 65-74.

ZANDEN, G. VAN DER, 1992b. Zwei neue Arten der Osmiini aus Marokko sowie Festlegung des Lectotypus von Hoplitis dumonti (Benoist). Reichenbachia, 29(12): 67-71.

ZANDEN, G. VAN DER, 1994a. Neue Arten paläarktischer Osmiini (Insecta, Hymenoptera, Apoidea, Megachilidae). Linzer Biologische Beiträge, 26(2): 1113-1124.

ZANDEN, G. VAN DER, 1994b. Neue Arten und Unterarten, eine Untergattung und einige neue Fälle von Synonymie der paläarktischen Bauchsammler (Insecta: Hymenoptera: Apoidea: Megachilidae). Reichenbachia, 30(27): 167-172.
ZANDEN, G. VAN DER, 1995. Zur Synonymie paläarktischer Arten der Familie Megachilidae (Insecta, Hymenoptera, Apoidea). Linzer Biologische Beiträge, 27(1): 427-434.

ZANDEN, G. VAN DER, 1996. Neue Arten und Synonymie bei paläarktischen Bauchsammlern (Hymenoptera aculeata, Apoidea, Megachilidae). Linzer Biologische Beiträge, 28(2): 883-895.

ZANDEN, G. VAN DER, 1998. Neue paläarktischer Arten aus der Familie der Megachilidae (Insecta, Hymenoptera, Apoidea). Linzer Biologische Beiträge, 30(2): 523527.
Recibido, 12-X-2006

Aceptado, 29-XI-2006 Publicado, 29-XII-2006 